\title{
A multi-zone combustion model with detailed chemistry including cycle-to-cycle dynamics for diesel engine control design
}

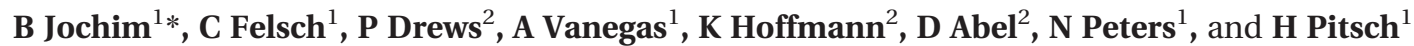 \\ ${ }^{1}$ Institut für Technische Verbrennung, RWTH Aachen University, Germany \\ ${ }^{2}$ Institut für Regelungstechnik, RWTH Aachen University, Germany \\ The manuscript was received on 19 September 2010 and was accepted after revision for publication on 17 March 2011.
}

DOI: $10.1177 / 0954407011406330$

\begin{abstract}
This paper reviews the research activities within the subproject B1 Model Reduction for Low-Temperature Combustion Processes through CFD-Simulations and Multi-Zone Models of the Collaborative Research Centre SFB 686 - Model-Based Control of Homogenized LowTemperature Combustion. The SFB 686 is carried out at RWTH Aachen University, Germany and Bielefeld University, Germany, and is funded by the German Research Foundation (DFG). This paper thereby summarizes the outcome of various publications by the authors, with the appropriate references given in the individual sections. Additionally, some new results are introduced.

The particular subject of this work is a dynamic simulation strategy for premixed charge compression ignition (PCCI) combustion that can be used in closed-loop control development. A detailed multi-zone chemistry model for the high-pressure part of the engine cycle is extended by a mean value gas exchange model accounting for the low-pressure part. Thus, an efficient model capable of describing PCCI combustion is sufficiently well established. In order to capture cycle-to-cycle dynamics, identified system dynamics influencing the input parameters are incorporated. For this, a Wiener model is set up that uses the combustion model as a nonlinear system representation. In this way, a dynamic nonlinear model for the representation of the controlled plant Diesel engine is created. The model is validated against transient experimental engine data.
\end{abstract}

Keywords: SFB 686, dynamic simulation environment, PCCI combustion, detailed chemistry, combustion model reduction, model-in-the-loop

\section{INTRODUCTION}

The looming shortage of crude oil and growing environmental concerns provide a strong drive for developing fuel-efficient vehicle technologies. The transportation sector is under particularly strong pressure, given its almost exclusive dependence on fossil fuels [1]. The expected explosive economic growth in Asia, particularly China and India, is accelerating the rate of increasing fuel demand and

*Corresponding author: Institut für Technische Verbrennung, RWTH Aachen University, Templergraben 64, D-52056 Aachen, Germany.

email:b.jochim@itv.rwth-aachen.de intensifying pressure on the fuel supply side. Although electric mobility is considered the dominant future powertrain technology, improved fuel efficiency for conventional powertrain systems remains the best alternative in the short- to midterm. Premixed charge compression ignition (PCCI), or premixed compression ignition (PCI), as it is sometimes referred to, has emerged as an interesting alternative to conventional Diesel combustion in the part-load operating range [2-4]. This concept involves relatively early injection timings, high external EGR rates, and cooled intake air, leading to a low-temperature combustion (LTC) process with low $\mathrm{NO}_{x}$ and particulate emissions. A general review of LTC processes is given by Dec [5]. However, in 
contrast to conventional Diesel combustion, with early direct-injection LTC it can be difficult to prevent combustion from occurring before top dead centre (TDC). This often increases noise and reduces engine efficiency. Sophisticated closed-loop control of the combustion process is one means to overcome this difficulty.

In the recent past, several efforts have been reported in the literature that aim at controlling engine combustion [6-12]. The standard procedure for creating a controller includes the modelling part as the first step [13-17]. Often these models differ in several aspects from models that include details of the combustion process, like three-dimensional computational fluid dynamics (CFD) models [1821]. From the viewpoint of automatic control, the dynamics describing the dependency of the system's outputs on the actors is of highest priority. Nevertheless, the nonlinear dependencies of the combustion process have to be covered in an appropriate manner, too. Another requirement is a calculation speed that is fast enough to incorporate the model in dynamic closed-loop simulations.

\section{MODELLING FRAMEWORK}

The conceptual idea of a continuous modelling chain for engine control applications was introduced by Albrecht et al. [13].

From a simple point of view, the models developed for engine control applications can be organized on a physical modelling level axis, from three-dimensional CFD models to look-up table models. Most of the time, a gain of predictive capability is obtained by increasing the model complexity and the CPU cost. For this reason, a modelling road-map focused on a specific level of this axis does not give the adapted environment to improve the general physical accuracy and maintain low CPU cost models. The modelling development through a continuous process is an interesting means to obtain a solid modelling approach, which takes its roots in the three-dimensional modelling and is based on a coherent chain from reference one-dimensional/ zero-dimensional models to look-up table models (see Fig. 1). For each modelling stage, the main advantages of such a development process are:

(a) to take benefit from a coherent framework thanks to the up-level models, which are used as a modelling guideline;

(b) to have access to detailed variables from the most accurate models to facilitate the refined validation of the new developments; (c) to offer an efficient validation tool, which allows to obtain the reference results with more flexibility than with an experimental test bed.

As represented in Fig. 1, experimental results are required for a complete model design and can easily be used at any stage of the model development.

This work targets the first reduction step that comprises the model reduction from two-dimensional/three-dimensional models to one-dimensional and multi-zone models. This target is highlighted in grey in Fig. 1.

\section{COMBUSTION MODEL FORMULATION}

Crucial for reacting turbulent flows is the adequate modelling of chemistry. Here, a multi-zone chemistry model is employed that is derived from a detailed three-dimensional CFD model. The multi-zone model covers the nonlinear dependencies within the highpressure part of the engine cycle sufficiently well.

\subsection{Combustion model reduction}

Recently, Barths et al. [22] developed a consistent mixing model for the two-way-coupling of CFD codes and zero-dimensional multi-zone codes, yielding a hybrid CFD/zonal modelling approach for HCCI chemistry that aims at reducing the computational overhead for large chemical mechanisms. There, all aspects except chemical kinetics were computed using three-dimensional CFD, and CFD cells were binned into a relatively small number of zones for the chemistry calculations. Each CFD cell was binned into one of 27 zones based on its fuel mixture fraction, dilution, and total enthalpy. Issues within the two-way-coupling included maintaining thermodynamic consistency between the two representations and interactions among zones. Following from there, an interactively coupled CFD-multi-zone approach was presented by Felsch et al. [23] that can be used to simulate HCCI combustion. Later, this interactively coupled CFD-multi-zone approach was applied for various PCCI operating conditions in a 1.91 FIAT GM Diesel engine [24]. In the same work, the interactively coupled CFD-multi-zone approach was systematically reduced towards a computationally efficient stand-alone multi-zone model. For this, the multi-zone model was decoupled from the CFD code. In the framework of the interactively coupled CFD-multi-zone approach, all relevant information fed from the CFD code to the multi-zone model was identified. This information was then modelled within the decoupled stand-alone multi-zone model. The 


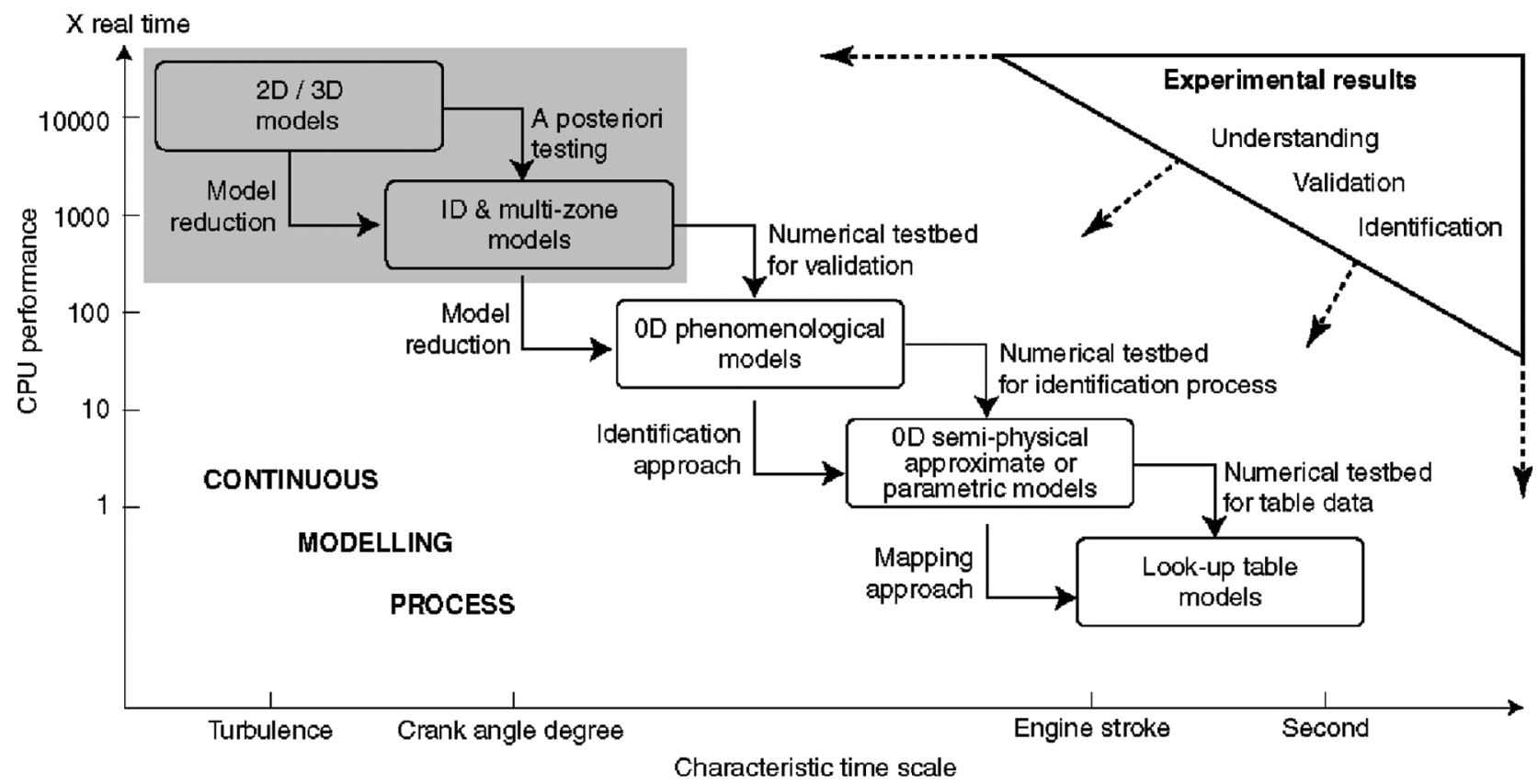

Fig. 1 Continuous modelling chain for engine control applications (adopted from Albrecht et al. $[13])$

validity of the reduction was limited to the investigated 1.91 FIAT GM Diesel engine that is also subject of this review. The stand-alone multi-zone model showed a significant advantage with respect to computational cost. Due to its strict derivation from the interactively coupled CFD-multi-zone approach, the stand-alone multi-zone model was at the same time nearly as predictive as the detailed CFD approach.

The theoretical background of the stand-alone multi-zone model and its validation is briefly summarized in the remainder of this section. For detailed information regarding the reduction methodology from the interactively coupled CFD-multizone approach towards the stand-alone multi-zone model, the reader is referred to Felsch et al. [24].

\subsection{Multi-zone combustion model}

The stand-alone multi-zone combustion model employed in the current study is X0D, a zerodimensional chemistry solver based on multiple zero-dimensional reactors. X0D was developed internally at General Motors R\&D by Hardo Barths, Tom Sloane, and Christian Hasse, and was first described by Hergart et al. [25] and Felsch et al. [26].

\subsubsection{Governing equations}

The equations governing species mass fractions, temperature, and pressure change in the multi-zone chemistry code are

$$
\begin{aligned}
\frac{\mathrm{d} Y_{i j}}{\mathrm{~d} t}= & \frac{1}{m_{i}} \sum_{k=1}^{n z} \dot{m}_{i k}\left(Y_{k j}^{e x}-Y_{i j}\right)+\frac{\dot{\omega}_{i j}}{\rho_{i}}+\frac{\dot{\rho}_{i j}^{s}}{\rho_{i}} \\
\frac{\mathrm{d} T_{i}}{\mathrm{~d} t}= & \frac{1}{m_{i} \cdot \bar{c}_{p i}} \sum_{k=1}^{n z} \dot{m}_{i k}\left(\bar{h}_{k}^{e x}-\bar{h}_{i}\right) \\
& -\frac{1}{m_{i} \cdot \bar{c}_{p i}} \sum_{j=1}^{n s p} h_{i j} \sum_{k=1}^{n z} \dot{m}_{i k}\left(Y_{k j}^{e x}-Y_{i j}\right) \\
& -\frac{1}{\rho_{i} \cdot \bar{c}_{p i}} \sum_{j=1}^{n s p} h_{i j} \cdot \dot{\omega}_{i j}+\frac{1}{\rho_{i} \cdot \bar{c}_{p i}} \frac{\mathrm{d} p}{\mathrm{~d} t} \\
& +\frac{1}{\rho_{i} \cdot \bar{c}_{p i}} \sum_{j=1}^{n s p} \dot{\rho}_{i j}^{s} \cdot \Delta h_{v j}-\frac{1}{m_{i} \cdot \bar{c}_{p i}} \dot{Q}_{\mathrm{wall}, i}
\end{aligned}
$$

and

$$
\begin{aligned}
\frac{\mathrm{d} p}{\mathrm{~d} t}= & -\frac{p}{V} \frac{\mathrm{d} V}{\mathrm{~d} t}+\frac{p}{V} \\
& \times \sum_{i=1}^{n z} V_{i}\left(\frac{1}{m_{i}} \frac{\mathrm{d} m_{i}}{\mathrm{~d} t}+\frac{1}{T_{i}} \frac{\mathrm{d} T_{i}}{\mathrm{~d} t}+\bar{W}_{i} \sum_{j=1}^{n s p} \frac{1}{W_{j}} \frac{\mathrm{d} Y_{i j}}{\mathrm{~d} t}\right)
\end{aligned}
$$

In equation (1), $Y_{i j}$ denotes the mass fraction of species $j$ in zone $i$, and $\dot{\omega}_{i j}$ is the corresponding chemical source term. $\dot{\rho}_{i j}^{s}$ accounts for the source term due to fuel vapourization. It is zero for all species except the fuel itself $\left(\dot{\rho}_{i j}^{s}=0, j \neq\right.$ fuel). The first term on the right-hand side of equation (1) describes the mass exchange between the zones, where $\dot{m}_{i k}$ is the rate at which mass is transported 
between zones $i$ and $k$, and $n z$ stands for the total number of zones. Similarly, in equation (1) the first and second term on the right-hand side represent the enthalpy exchange between zones due to enthalpy stratification between zones and due to species stratification between zones, respectively. $\Delta h_{v j}$ denotes the latent heat of vapourization of species $j$, and $\dot{Q}_{\text {wall, } i}$ is the wall heat transfer of zone $i$. In equations (2) and (3), nsp stands for the number of species employed in the underlying chemical mechanism. The equation of state is used to derive equation (3), which solves for the pressure across all zones. Through this equation, all zones are thermodynamically coupled with each other.

Mixing in the multi-zone model is accounted for by allowing the different zones to exchange mass and energy with each other, in addition to the interaction through the pressure. They exchange their scalar quantities (species composition and enthalpy) based on the rate at which they exchange their mass.

\subsubsection{Heat transfer to the walls}

Wall heat transfer is described as

$$
\dot{Q}_{\text {wall }, i}=\sum_{l=1}^{n_{\text {wall }}} A_{\text {wall }, l, i} \cdot h_{\text {wall }, l, i}\left(T_{i}-T_{\text {wall }, l}\right)
$$

where $n_{\text {wall }}$ denotes the total number of walls in the engine. $A_{\text {wall, } l, i}$ is the area of wall $l$ belonging to zone $i, h_{\text {wall, } l, i}$ the heat transfer coefficient of zone $i$ to wall $l, T_{i}$ the temperature of zone $i$, and $T_{\text {wall, }, l}$ the temperature of wall $l$. The heat transfer coefficient $h_{\text {wall }, l, i}$ is modeled with the Woschni correlation ([27]). The Woschni correlation reads

$$
\begin{aligned}
h_{\text {wall }, l, i}=h_{\text {wall }}= & 3.26 \cdot b^{-0.2 .} \\
& p^{0.8} \cdot T_{\mathrm{av}}^{-0.53}\left(C_{1} \cdot v_{\text {piston }}\right)^{0.8}
\end{aligned}
$$

where $b$ is the bore of the engine, $p$ the mean cylinder pressure, $T_{\mathrm{av}}$ the average in-cylinder temperature, and $v_{\text {piston }}$ the mean piston speed. The constant $C_{1}$ is adjustable and is set to 0.5 . Since the average in-cylinder temperature $T_{\mathrm{av}}$ is used within the Woschni correlation and $h_{\text {wall } l, i}$ does not depend on any specific wall, the heat transfer coefficient is equal for all zones, leading to $h_{\text {wall }, l, i}=h_{\text {wall }}$.

For the specific engine investigated, the area $A_{\text {wall, },, i}$ of wall $l$ belonging to zone $i$ has to be taken from a preceding simulation with the interactively coupled CFD-multi-zone approach mentioned above. Then, this information can be incorporated into a successive simulation with the stand-alone multi-zone model.

\subsubsection{Fuel injection and vapourization}

A preceding simulation with the interactively coupled CFD-multi-zone approach also allows for determining the amount of fuel that is injected and vapourizes in each CFD zone. This information can then be incorporated into a successive simulation with the stand-alone multi-zone model (see source term $\dot{\rho}_{i j}^{s}$ in equations (1) and (2)).

\subsubsection{Mixing model}

The mixing model within the stand-alone multizone model assumes that the mass exchange rate $\dot{m}_{i k}$ of zone $i$ with neighbouring zone $k$ (see equations (1) and (2)) is proportional to the wall heat transfer coefficient $h_{\text {wall }}$ and to the area $A$ both zones share (see $[\mathbf{2 5}]$ ). This is an analogy to the well-known empirical Lewis law, which assumes a similarity between heat and mass transfer (see [28]). The heat transfer to the walls and the mass exchange between the zones are both induced by the turbulence intensity so that they can be related to each other. The corresponding equation reads

$$
\dot{m}_{i k}=r_{\mathrm{M} B} \cdot A \cdot \frac{m_{i}+m_{k}}{\left(m_{i} \bar{c}_{p i}+m_{k} \bar{c}_{p k}\right)} \cdot h_{\mathrm{wall}}
$$

In equation (6), $\bar{c}_{p i}$ is the average heat capacity at constant pressure of zone $i . r_{\mathrm{M} B}$ is a parameter that is adjusted to yield the desired level of mixing. The area $A$ is computed from the volumes $V_{i}$ and $V_{k}$ of the two zones $i$ and $k$ according to

$$
A=4 \pi\left[\frac{3}{4 \pi}\left(V_{i}+V_{k}\right)\right]^{\frac{2}{3}}
$$

In the adiabatic limit, no heat is transferred from the in-cylinder to the engine walls. Nevertheless, the wall heat transfer coefficient itself does not become zero in this case (see equations (5)). For this reason, this mixing model also captures the adiabatic limit.

In the following, some aspects of the systematic reduction procedure from the interactively coupled CFD-multi-zone approach towards the stand-alone multi-zone model are discussed. It is possible to evaluate the choice of the parameter $r_{\mathrm{MB}}$ in equation (6) by means of a preceeding simulation with the interactively coupled CFD-multi-zone approach (details are given in reference [24]). Figure 2 displays the average parameter $r_{\mathrm{M} B}$ around TDC firing for a selected operating condition (SOI at $-26 \mathrm{deg}$ 


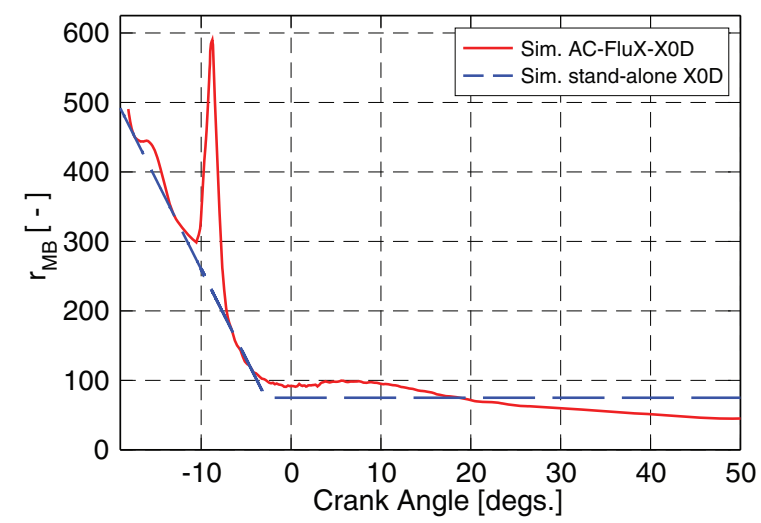

Fig. 2 Average parameter $r_{\mathrm{M} B}$ as extracted from the interactively coupled CFD-multi-zone approach (denoted as AC-FluX-X0D) and as incorporated into the stand-alone multi-zone model for one selected operating condition (SOI at $-26 \mathrm{deg}$ CA aTDC, external EGR rate of 30 percent, injected fuel mass of $10.2 \mathrm{mg} /$ cycle)

CA aTDC, external EGR rate of 30 per cent, injected fuel mass of $10.2 \mathrm{mg} /$ cycle), as extracted from a simulation with the interactively coupled CFDmulti-zone approach and as incorporated into the stand-alone multi-zone model. For incorporation, $r_{\mathrm{M} B}$ was set to 75.0 during compression and expansion, with a linear increase up to 500.0 during injection and a linear decrease back again to 75.0 after end of injection. Qualitatively, both evolutions are similar. Altogether, $r_{\mathrm{M} B}$ decreases after EOI with decaying turbulence intensity after EOI. The evolution of $r_{\mathrm{M} B}$ as calculated from the interactively coupled CFD-multi-zone approach reveals two peaks. These two peaks are due to first- and secondstage ignition. The corresponding integral average of the whole simulation is 169.7.

The SOI variation shown below was also investigated in a previous work by Felsch et al. [29], with just one constant value of 100.0 being chosen for $r_{\mathrm{MB}}$, which is of the same order of magnitude as 169.7. In [29], the overall simulation results for the stand-alone multi-zone model in terms of pressure curves, IMEP ${ }_{\mathrm{HP}}$, CA10, CA50, CO emissions, combustion efficiency, and $\mathrm{NO} / \mathrm{NO}_{x}$ emissions were not as accurate in predicting the experimental results as the ones presented in the current work, where the evolution of $r_{\mathrm{M} B}$ was qualitatively adjusted to the one of the three-dimensional approach such that the stand-alone multi-zone model was capable of covering the combustion process for the investigated operating range.

It should be emphasized, too, that the order of magnitude of the parameter $r_{\mathrm{M} B}$ strongly depends on the level of premixing. In Hergart et al. [25], where more advanced injection timings were investigated, a constant value of 6.0 was sufficient for $r_{\mathrm{MB}}$. Therefore, this modelling parameter must be adjusted for each engine type.

\subsubsection{Chemistry model}

Combustion chemistry in X0D is described by a detailed chemical mechanism that comprises 59 elementary reactions among 38 chemical species. This mechanism describes low-temperature autoignition and combustion of n-heptane, which serves as a surrogate fuel for Diesel in this work. In addition, it accounts for thermal NO formation. The chemical mechanism for $\mathrm{n}$-heptane was constructed by Peters et al. [30]. The NO-submechanism, which is part of the full mechanism, is the extended Zeldovich mechanism (see for example [31]).

\subsubsection{Computational accuracy and efficiency}

The stand-alone multi-zone model does not solve for the solution of the flow field. This yields a significant advantage in computational costs in comparison to three-dimensional CFD modelling approaches. The run time for the stand-alone multizone model is approximately 3.3 minutes per highpressure engine cycle for a simulation with 15 zones on a Dell PowerEdge 1950 with two Intel Xeon Dual-Core CPUs with $3.0 \mathrm{GHz}$ (Woodcrest 5160). For such a simulation, the stand-alone multi-zone model written in FORTRAN 77 was compiled with the Intel Fortran Compiler 9.1.043. However, modelling the CFD information according to the procedure outlined above may reduce the accuracy of the simulation outcome. A detailed discussion of the computational accuracy and efficiency of the standalone multi-zone model can also be found in [24].

\subsection{Stationary validation}

At the Institute for Combustion Technology at RWTH Aachen University, Germany, experiments were carried out with a 1.91 GM Fiat Diesel engine. This engine is equipped with a second-generation Bosch Common-Rail injection system and an EDC16 electronic control unit. All relevant engine data are provided in Table 1. The mounting of the engine on the test bench is shown in Fig. 3.

A more detailed description regarding the engine, the test cell equipment, and the injection rate measurements can be found in Vanegas et al. [32].

The engine was operated at part-load conditions with a speed of $2000 \mathrm{r} / \mathrm{min}$. For this study, 50 different stationary experiments were carried out with variations in start of injection (SOI), external EGR rate, and total fuel mass injected. 
Table 1 GM Fiat engine specifications

\begin{tabular}{ll}
\hline Engine type: & $\begin{array}{l}\text { Four-cylinder } \\
\text { research engine } \\
1910 \mathrm{~cm}^{3}\end{array}$ \\
Displacement volume: & $82.0 \mathrm{~mm}$ \\
Bore: & $90.4 \mathrm{~mm}$ \\
Stroke: & $90.0 \mathrm{~mm}$ \\
Bore distance: & $145.0 \mathrm{~mm}$ \\
Connecting rod length: & $17.5: 1$ \\
Compression ratio: & 7 -hole injector \\
Injection System: & 100.0 degrees \\
Included spray angle: & $0.141 \mathrm{~mm}$ \\
Hole diameter: & 2.5 \\
Swirl number: & Diesel \\
Fuel: &
\end{tabular}

Figures 4 to 6 show simulation results obtained with the stand-alone multi-zone model in terms of pressure curve, indicated mean effective pressure of the high-pressure cycle (IMEP ${ }_{\mathrm{HP}}$ ), crank angle of 10 per cent and 50 per cent burnt fuel mass (CA50), as well as $\mathrm{CO}$ emissions in $\mathrm{g} / \mathrm{kg}$ fuel in the exhaust gas and combustion efficiency in per cent in comparison to test bench measurements for five selected operating conditions (SOI variation from -36 until -16 deg CA aTDC with an external EGR rate of 30 per cent and an injected fuel mass of $10.2 \mathrm{mg} /$ cycle). There is a very good qualitative and quantitative agreement between simulation and experiment, except for the $\mathrm{IMEP}_{\mathrm{HP}}$ of the operating conditions with an SOI of $-26,-21$ and -16 deg CA aTDC. The deviances at these conditions originate from small penalties in the combustion efficiency compared to the experiments. The lower combustion efficiency is caused by less complete combustion, which in turn leads to a slightly lower pressure level in the expansion stroke. Nevertheless, even at these conditions the agreement between simulation and experiment is sufficiently well.

Finally, Fig. 7 presents a comparison between numerically and experimentally obtained $\mathrm{NO} / \mathrm{NO}_{x}$ emissions in $\mathrm{g} / \mathrm{kg}$ fuel in the exhaust gas for the SOI variation. There is a good agreement. Note that the chemical mechanism used in the stand-alone multizone model simulations only accounts for thermal $\mathrm{NO}$ (see also section 3.2.5), while both $\mathrm{NO}$ and $\mathrm{NO}_{2}$ emissions are measured in the experiments. $\mathrm{NO}$ and $\mathrm{NO}_{2}$ emissions are usually grouped together as $\mathrm{NO}_{x}$ emissions, with NO being the predominant oxide of nitrogen produced inside the engine cylinder (see for example [31]).

\section{GAS EXCHANGE MODELLING}

The stationary validation described in the previous section is restricted to the high-pressure part of the engine cycle. The usage of the stand-alone multizone model within a closed-loop controller for PCCI combustion requires that it is capable of predicting the dependency of the controlled variables on the actuators, which are SOI, the external EGR rate, and the total fuel mass injected. The controlled variables are the IMEP and CA50. The latter is directly obtained from a simulation with the stand-alone multi-zone model. The former, however, can only be predicted for the time frame from closing of the intake until opening of the exhaust valves. For this

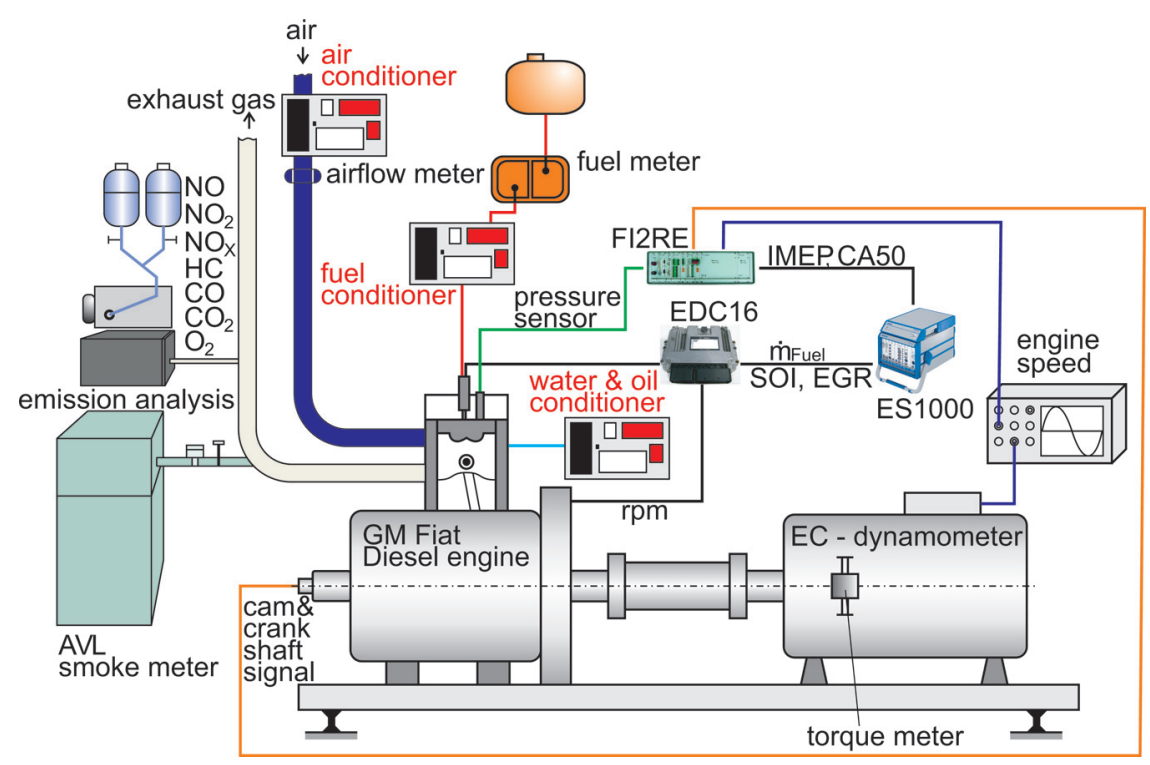

Fig. 3 Engine test bench 


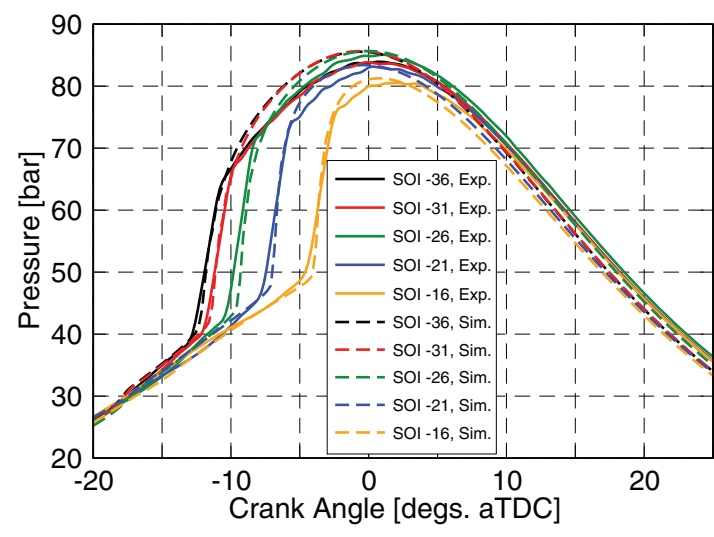

(a)

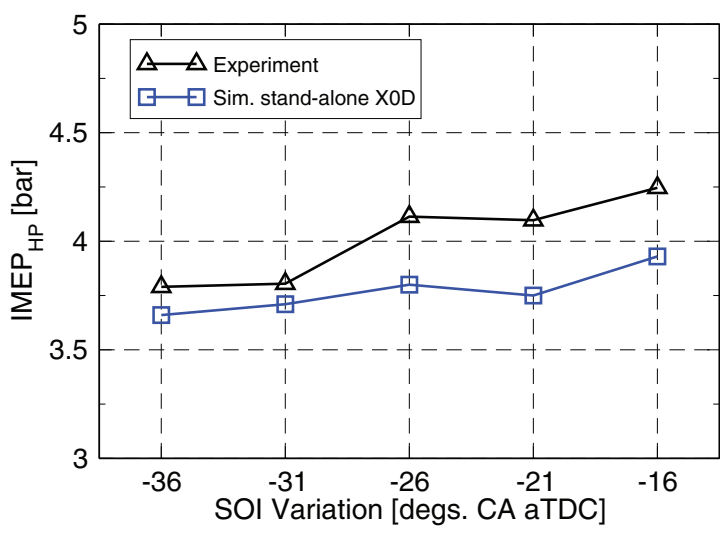

(b)

Fig. 4 Average cylinder pressure (left) and $\mathrm{IMEP}_{\mathrm{HP}}$ (right) for five selected operating conditions (SOI variation from -36 to $-16 \mathrm{deg}$ CA aTDC with an external EGR rate of 30 per cent and an injected fuel mass of $10.2 \mathrm{mg} /$ cycle). Comparison between stand-alone multi-zone model simulation and experiment

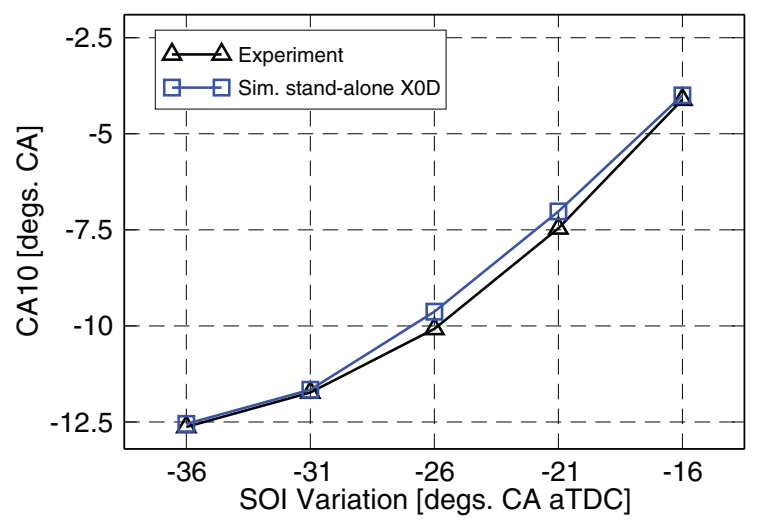

(a)

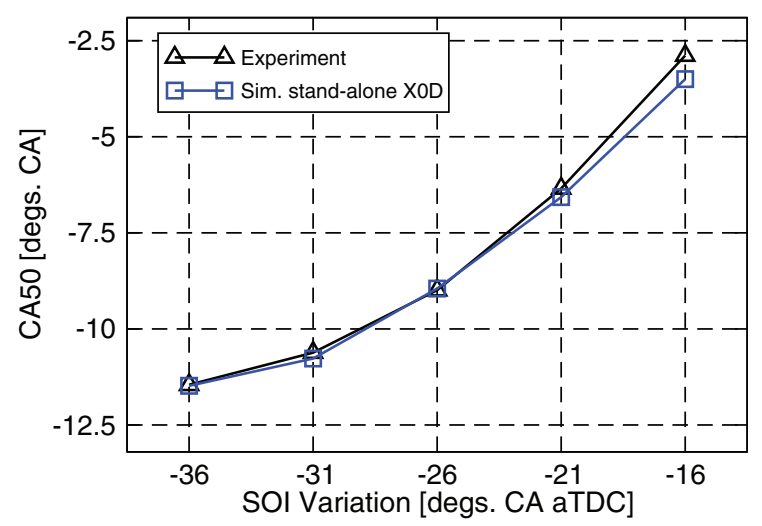

(b)

Fig. 5 CA10 (left) and CA50 (right) for five selected operating conditions (SOI variation from -36 to -16 deg CA aTDC with an external EGR rate of 30 per cent and an injected fuel mass of $10.2 \mathrm{mg} /$ cycle). Comparison between stand-alone multi-zone model simulation and experiment

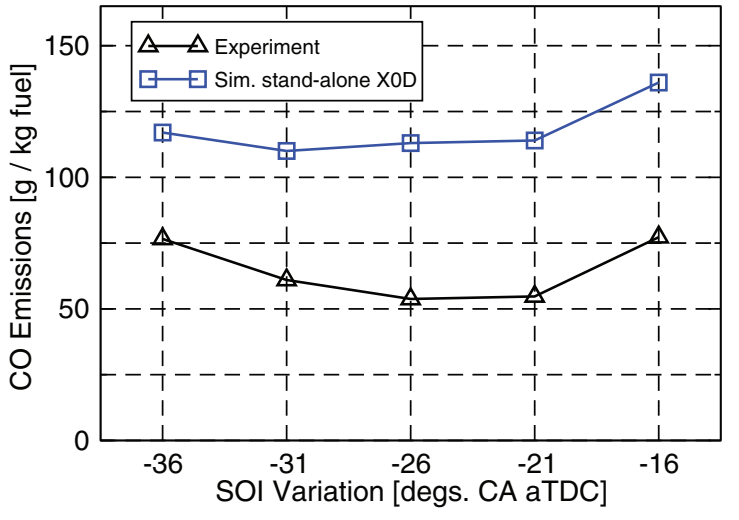

(a)

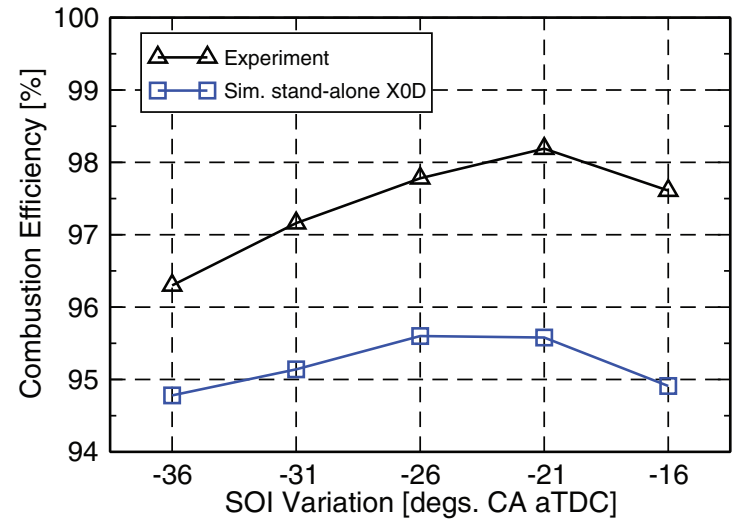

(b)

Fig. $6 \mathrm{CO}$ emissions in $\mathrm{g} / \mathrm{kg}$ fuel in the exhaust gas (left) and combustion efficiency in per cent (right) for five selected operating conditions (SOI variation from -36 to -16 deg CA aTDC with an external EGR rate of 30 percent and an injected fuel mass of $10.2 \mathrm{mg} / \mathrm{cycle}$ ). Comparison between stand-alone multi-zone model simulation and experiment 


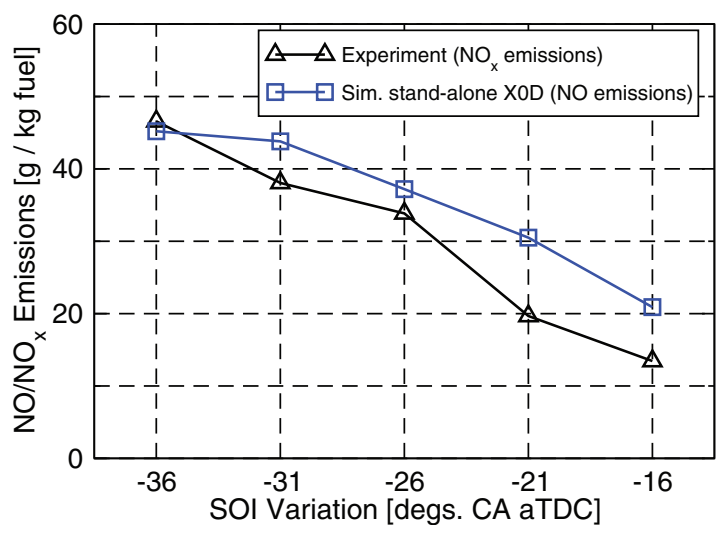

Fig. $7 \mathrm{NO} / \mathrm{NO}_{x}$ emissions in $\mathrm{g} / \mathrm{kg}$ fuel in the exhaust gas for five selected operating conditions (SOI variation from -36 to -16 deg CA aTDC with an external EGR rate of 30 percent and an injected fuel mass of $10.2 \mathrm{mg} /$ cycle). Comparison between stand-alone multi-zone model simulation and experiment

reason, the calculation of the $\mathrm{IMEP}_{\mathrm{HP}}$ is extended to the gas exchange part of the engine cycle.

The IMEP of the whole engine cycle is composed of the high-pressure part and the part describing the losses caused by the gas exchange. From the viewpoint of automatic control, a model predicting the accumulated losses occurring from exhaust valve opening until intake valve closing is sufficient. Furthermore, as one aim of this work is model reduction, the lowest acceptable approach in terms of detail level and calculation time is desired. Thus, a mean value model for the gas exchange is presented in the following. Nevertheless, if desirable, many commercially available software packages exist for a more detailed calculation of the gas exchange part of the engine cycle (for example the WAVE code [33] or the GT-POWER code [34]).

The calculation of the indicated mean effective pressure throughout the gas exchange $\left(\mathrm{IMEP}_{\mathrm{GE}}\right)$ is physically inspired by pumping losses. This approach was introduced by Hoffmann et al. [35] and is derived from the model of Richert [36]. The main aspects are presented in the following. The $\mathrm{IMEP}_{\mathrm{GE}}$ is given by

$$
\begin{aligned}
\operatorname{IMEP}_{\mathrm{GE}}= & x_{1} \cdot\left(p_{\mathrm{ae}}-p_{\mathrm{be}}\right)+x_{2} \cdot \sqrt{p_{\mathrm{ae}}-p_{\mathrm{be}}} \\
& +p_{\mathrm{be}} \cdot\left(x_{3} \cdot \frac{p_{\mathrm{be}}}{T_{\mathrm{be}}}+x_{4} \cdot \sqrt{\frac{p_{\mathrm{be}}}{T_{\mathrm{be}}}}\right) \\
& +x_{5} \cdot \sqrt{T_{\mathrm{ae}}-T_{\mathrm{be}}}+x_{6}
\end{aligned}
$$

Equation (8) includes terms of the volume flow through an orifice and through a throttle, as well as the dependency on the volumetric efficiency or on the density at the intake, respectively. The latter is represented by the fraction $p_{\mathrm{be}} / T_{\mathrm{be}}$, which is related to the

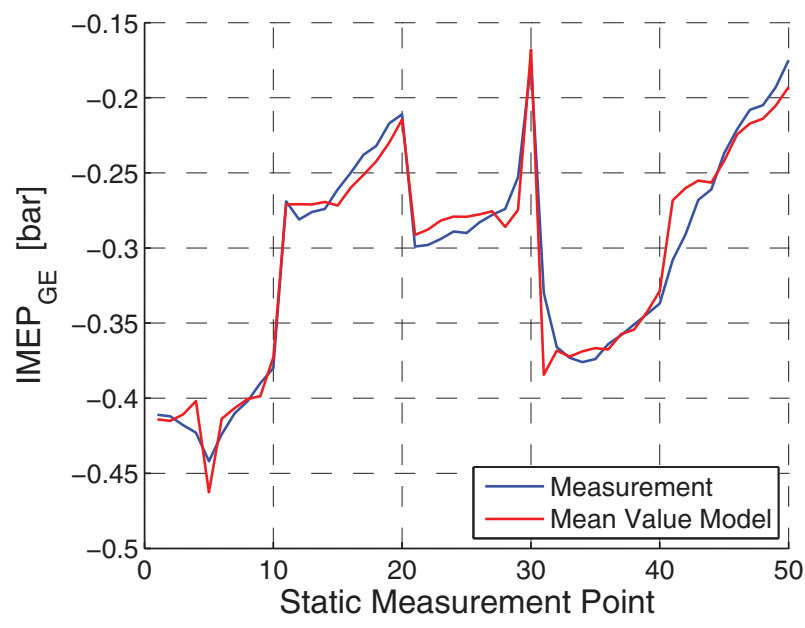

Fig. 8 IMEP $_{\mathrm{GE}}$ of the gas exchange for all 50 experiments mentioned previously. Comparison between mean value model calculation and experiment

ideal gas law $\rho=p / R T=$ const $\cdot p / T$. The enginedependent constants $x_{1}, x_{2}, x_{3}, x_{4}, x_{5}$, and $x_{6}$ need to be determined by fitting against experimental data.

The mean value model for the gas exchange depends on the state directly after and before the combustion process or the manifolds after and before the engine, respectively. In equation (8), these states are denoted with the subscripts 'ae' and 'be'. Inputs to the model from the exhaust manifold (that is, $p_{\mathrm{ae}}$ and $T_{\mathrm{ae}}$ ) can be taken from the highpressure calculation with the stand-alone multizone model, while the inputs to the model from the intake manifold (that is, $p_{\text {be }}$ and $T_{\text {be }}$ ) become influencing variables to the plant model. These influencing variables can serve as a disturbance input within the closed-loop control.

After appropriately fitting the above-mentioned constants, the approach is capable of predicting the $\mathrm{IMEP}_{\mathrm{GE}}$ within 5 percent accuracy for most of the 50 operating conditions mentioned previously (see Fig. 8).

Combining the stand-alone multi-zone model $\mathrm{X} 0 \mathrm{D}$ with this gas exchange model therefore leads to a combustion model, which can be used to determine the static dependency of the controlled variables IMEP and CA50 on the actuated variables SOI, external EGR rate, and total fuel mass injected. Influencing inputs are the pressure and temperature in the intake manifold.

\section{IDENTIFICATION OF CYCLE-TO-CYCLE ENGINE DYNAMICS}

The combination of stand-alone multi-zone combustion model and mean value model for the 


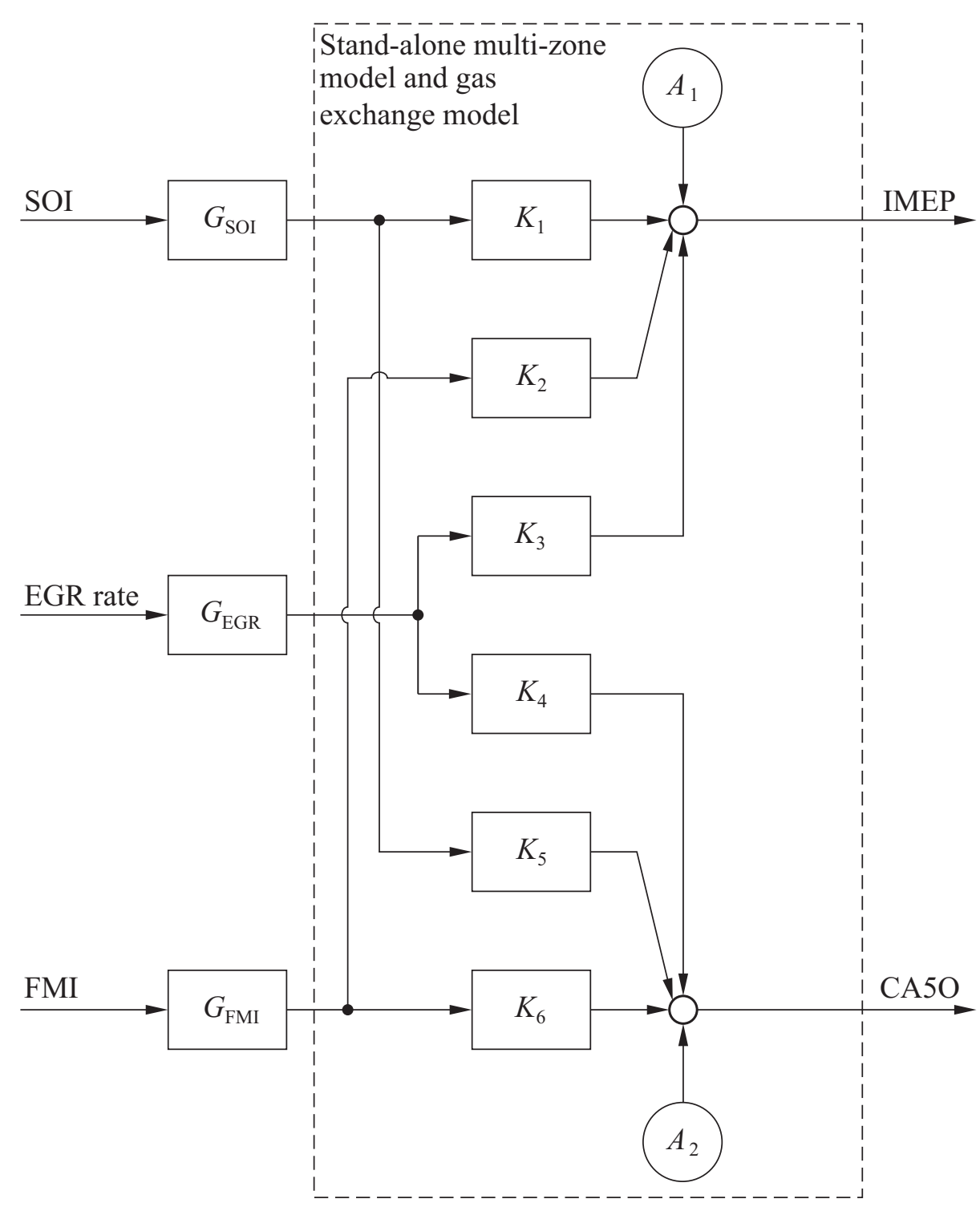

Fig. 9 Model structure used for identifying the system's dynamic time-discrete transfer functions. The dashed line shows the part that is substituted by the complete integrated static model after the system identification

$\mathrm{IMEP}_{\mathrm{GE}}$ of the gas exchange is suitable to reproduce and predict the engine combustion thermodynamics for static engine operation. However, it does so far not include any dynamics of the controlled variables. Hence, a structure has to be chosen, which is suitable for adding the dynamic aspect to the static accurate model. In control theory, two types of models or a combination of both have been established for this purpose: Wiener and Hammerstein models (see for example [37, 38]). As the dynamic physical behaviour of the real engine shall be enforced on the whole static model, a Wiener-type dynamics was chosen by Hoffmann et al. [35]. With this choice, the inputs to the static model are overlaid with time attributes, which enforce the dynamic behaviour on the combustion simulation. Thus, IMEP and CA50 are consequently affected by the dynamics to be identified. Figure 9 depicts the implemented approach. Here, the static nonlinear behaviour is described by the combined integrated static model, or alternatively by the two offset values $A_{1}$ and $A_{2}$ and the gains $K_{1}$ through $K_{6}$, respectively. For the system identification described in this section, the latter alternative is used, where the two offset values $A_{1}$ and $A_{2}$ and the gains $K_{1}$ through $K_{6}$ are dependent on the operating point due to the system's nonlinearity.

As only load-transient conditions with a static engine speed are regarded as a first step, the identified dynamics are assumed to be given by a $P T_{1}$ element (first-order lag element). If speed-transient conditions would additionally apply, this approach 
would either have to be extended by time constants tabulated over engine speed or by a physical model for the mechanical dynamics of pistons, conrods, crank, and additionally gas exchange, respectively. The total model would still have to be fitted to measurements as well. With the latter approach, the unknown masses and inertias of the drivetrain, as well as parameters of the gas dynamics need to be identified. An example for such an approach is the work by Schulze et al. [39].

A description of the dynamics from the system's inputs SOI, external EGR rate, and total fuel mass injected (FMI) towards the outputs IMEP and CA50 is needed. For this purpose, several approaches for arranging experiments exist in the literature. In this regard, step responses are the most common way for the identification of a system's dynamics. The experimental set-up realizes this by using an ES1000 system by ETAS as the central unit for impressing the steps on the actuated variables, as well as for simultaneously collecting the data of the step responses in the controlled variables. More details regarding this Rapid Control Prototyping system by ETAS can be found in the user manual by [40]. The steps in the actors were enabled by an ETK-connection of the ES1000 system to the engine's electronic control unit (ECU, type EDC16). The physical actor for the SOI and the total fuel mass injected obviously is the Common-Rail direct injector, while for the EGR rate there is no explicit acting device. For this, the EGR rate is changed by the combination of the actors EGR valve and variable geometry turbine (VGT) position. It is impossible to make the engine step in EGR rate. Nevertheless, the system shows a dynamic response to a change in the EGR rate caused by a simultaneous step in EGR valve and VGT position. For the operating points to step between, the corresponding values for EGR throttle and VGT position were determined for a steady state operation. Furthermore, the test bed offers no direct possibility to measure the dynamics of the EGR rate, which is the input and actuating variable for our model. Commonly, in modern ECUs in series applications, the mass flow of fresh air aspirated by the engine is measured instead (see [41]). The EGR rate can be calculated by

$$
\text { EGR rate }=\frac{\dot{m}_{\mathrm{EGR}}}{\dot{m}_{\text {trapp }}}=\frac{\dot{m}_{\text {trapp }}-\dot{m}_{\text {air }}}{\dot{m}_{\text {trapp }}}
$$

where $\dot{m}_{\text {air }}$ denotes the mass flow of fresh air. The total trapped gas mass $\dot{m}_{\text {trapp }}$ mainly depends on the revolution speed, as well as on the pressure and temperature in the intake manifold. The engine was run at a constant revolution speed. In addition, the intake manifold conditions did not vary significantly during the step response experiments. The total trapped gas mass $\dot{m}_{\text {trapp }}$ is therefore considered approximately constant and, for this reason, the main dynamics affecting the EGR rate in this case is the same but negative dynamics as with the fresh air mass $\dot{m}_{\text {air }}$. This was measured by the engine's ECU, but also handed over to the measuring device ES1000 via ETK. Because the steady state value for the EGR rate is known before and after applying the step in VGT position and EGR valve, the dynamic EGR rate during the tests can be recalculated and used as an input to the model.

Another prerequisite for the system identification is the measurement of the target values or outputs of the model, respectively. Both IMEP and CA50 are calculated from the pressure progression measurement. This has to be realized by an additional device, as in series applications no pressure analysis is implemented in the ECU. In this work, a FI2RE system by [42] is used. It analyses the pressure signal in real time and hands it over to the measurement system ES1000 via CAN.

The step response experiments provide a dataset containing the temporally resolved signals for SOI, external EGR rate, and FMI, as well as the corresponding response in IMEP and CA50. The aim of the extraction of the system's dynamics is the above-mentioned Wiener-type dynamics. The advantage of this approach is also its disadvantage. By assigning the system's dynamics to the inputs, a relatively simple model structure concerning the dynamic transfer functions is achieved, as their number is reduced to the number of inputs (see Fig. 9). But this also is the main drawback of the approach, because all three inputs influence both outputs. This results in six dynamic dependencies, which have to be described by three transfer functions. The dynamic effects on IMEP and CA50 excited by the changes in SOI thus have to be represented by a transfer function $G_{\mathrm{SOI}}$, the dynamic influence on both outputs caused by changes in the external EGR rate or the total fuel mass injected by a transfer function $G_{\mathrm{EGR}}$ or $G_{\mathrm{FMI}}$, respectively.

The transfer function $G_{\text {SOI }}$ can be determined from the evaluation of the responses of IMEP and CA50 to steps in SOI. The same sampling rate as used during the measurements with the ES1000 system was used for the time-discrete transfer function. The sampling rate $T_{\mathrm{S}}$ of the calculation of IMEP and CA50 is preset by the engine's revolution speed and is given by

$$
T_{\mathrm{s}}=\frac{2 \cdot 60 \mathrm{~s} / \mathrm{min}}{n_{\mathrm{eng}}[\mathrm{r} / \mathrm{min}]}
$$


With $n_{\text {eng }}=2000 \mathrm{r} / \mathrm{min}$, a new value for IMEP and CA50 is calculated every 0.06 seconds. To ensure compliance with Shannon's theorem, the measurements were sampled with 0.01 seconds, and consequently the same sample time was chosen for the time-discrete transfer function.

In mathematics and signal processing, the $Z$ transform converts a discrete time-domain signal, which is a sequence of real or complex numbers, into a complex frequency-domain representation (see for example [43]). It is the discrete equivalent of the Laplace transform. The discrete time-domain function $f\left(k \times T_{\text {spl }}\right)$ of sample time $T_{\text {spl }}$ is transformed to a $z$-domain transfer function $F(z)_{\left(T_{\mathrm{spl}}\right)}$ valid for the specified sample time. In this representation, $z$ can be understood as a time shift operator: $x\left(k \times T_{\text {spl }}-n \times T_{\text {spl }}\right)\left\llcorner\smile \bullet z^{-n} X(z)_{\left(T_{\text {sp }}\right)}\right.$. The measurements indicate the use of a $P T_{1}$-transfer function. With a sample time of 0.01 seconds the identified $P T_{1}$-element is given by

$$
G(z)_{\text {SOI },(0.01)}=\frac{\widehat{\text { SOI }}}{\text { SOI }}=\frac{0.1}{z-0.9}
$$

Here, the hat indicates the temporal attribute of the signal. Selected results of this identification are shown in Fig. 10. For the system identification, the corresponding static gains $K_{1}$ through $K_{6}$ and the two offset values $A_{1}$ and $A_{2}$ were adjusted to the operating point to substitute the complete integrated static model.

The sampling rate used here is obviously not consistent with the revolution speed. The static integrated model is executed every engine cycle, demanding a sample time of 0.06 seconds for $2000 \mathrm{r} / \mathrm{min}$. To remedy this problem and to enable the implementation of the transfer function into the integrated model, the time-discrete transfer function is resampled with the new sample time of 0.06 seconds to

$$
G(z)_{\mathrm{SOI},(0.06)}=\frac{\widehat{\mathrm{SOI}}}{\mathrm{SOI}}=\frac{0.4686}{z-0.5314}
$$

In an analogous manner, the transfer functions $G(z)_{\mathrm{EGR}}$ and $G(z)_{\mathrm{FMI}}$ can be determined from the evaluation of the responses of IMEP and CA50 to the dynamic EGR rate or dynamic total fuel mass injected signal, respectively. Here, the EGR rate signal is recalculated as described above. The corresponding gains and offset values in Fig. 9 are again adjusted such that the static nonlinear transfer behaviour is met. The fit of the system's dynamics is evaluated with a measuring sample time of $0.01 \mathrm{sec}-$ onds and resampled to 0.06 seconds afterwards.
The influence of the external EGR rate is described by

$$
G(z)_{\mathrm{EGR},(0.01)}=\frac{\mathrm{EGR} \mathrm{rate}}{\text { EGR rate }}=\frac{0.015}{z-0.985}
$$

and can be resampled with $T_{s}=0.06$ seconds to

$$
G(z)_{\mathrm{EGR},(0.06)}=\frac{\mathrm{EGR} \mathrm{rate}}{\text { EGR rate }}=\frac{0.08669}{z-0.9133}
$$

Using equation (13), the results shown in Fig. 11, among others, could be achieved.

For the dynamic dependency of the model's outputs on the total fuel mass injected the transfer function

$$
G(z)_{\mathrm{FMI},(0.01)}=\frac{\widehat{\mathrm{FMI}}}{\mathrm{FMI}}=\frac{0.071}{z-0.9290}
$$

was determined, which leads to the resampled transfer function

$$
G(z)_{\mathrm{FMI},(0.06)}=\frac{\widehat{\mathrm{FMI}}}{\mathrm{FMI}}=\frac{0.3572}{z-0.6428}
$$

The results for the response in IMEP and CA50 to a step in FMI from $15 \mathrm{mg} /$ cycle to $25 \mathrm{mg} /$ cycle and back (with an SOI of -35.7 deg CA aTDC and an external EGR rate of 45 percent) are depicted in Fig. 12. Note that for the identification of $G(z)_{\mathrm{FMI},(0.01)}, G(z)_{\mathrm{EGR},(0.01)}$ has to be identified first, as it is impossible to vary FMI without changing EGR, if VGT and EGR valve are not adjusted to the new load condition.

\section{INTEGRATED MODEL}

This section shows the realization of an integrated model composed of the stand-alone multi-zone model, the gas exchange model, and the identified system dynamics within a suitable test environment for control applications. The integrated model was briefly introduced by Felsch et al. [24]. Here, the main contents are reviewed and some additional aspects are discussed.

For application within a closed-loop control simulation, the stand-alone multi-zone combustion model with detailed chemistry kinetics was transferred to an environment suitable for the development and testing of controllers. The stand-alone multi-zone model X0D written in FORTRAN 77 was embedded into a MATLAB $^{\circledR} /$ SIMULINK $^{\circledR}$ Fortran s-function, enabling the simulation of 


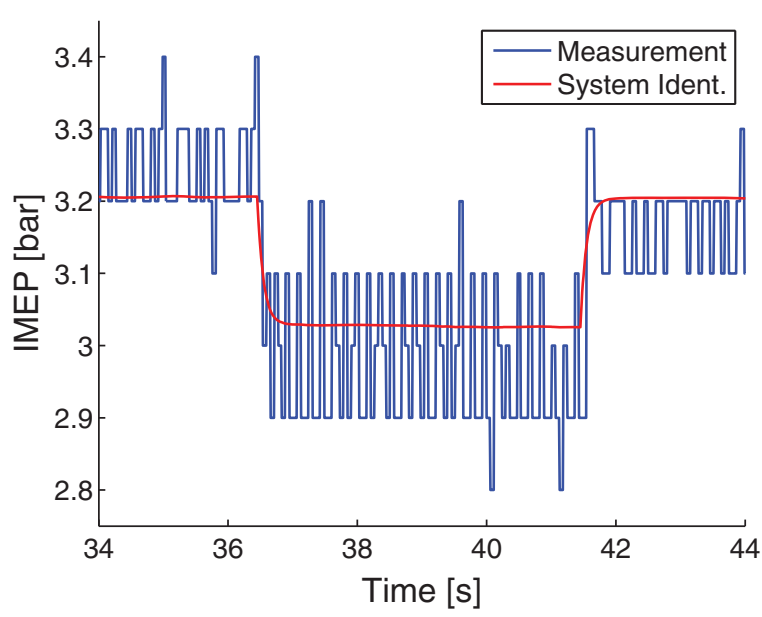

(a)

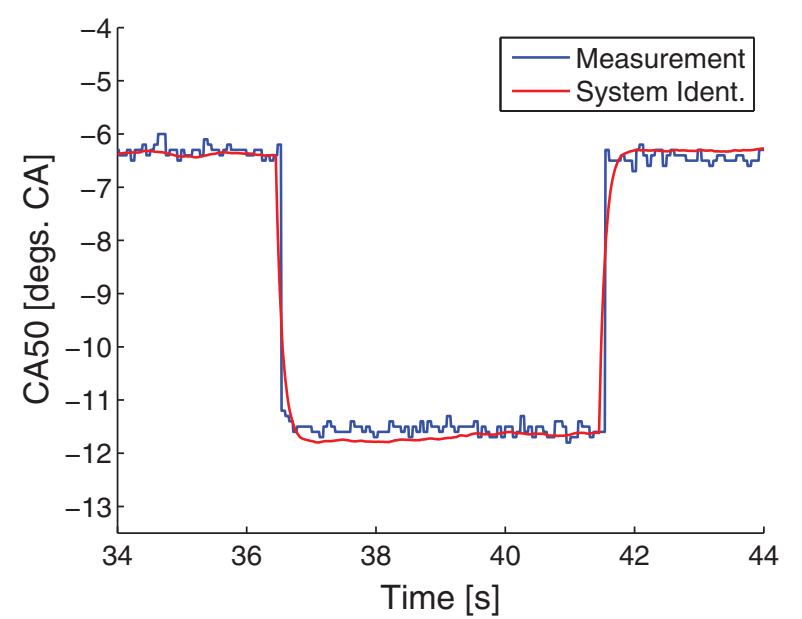

(b)

Fig. 10 Comparison between experiment and system identification with identified discrete transfer function $G(z)_{\text {SOI, (0.01) }}$. IMEP (left) and CA50 (right) for an SOI step from -20.7 to -30.7 deg CA aTDC and back with an external EGR rate of 30 per cent and an injected fuel mass of $10.2 \mathrm{mg} / \mathrm{cycle}$

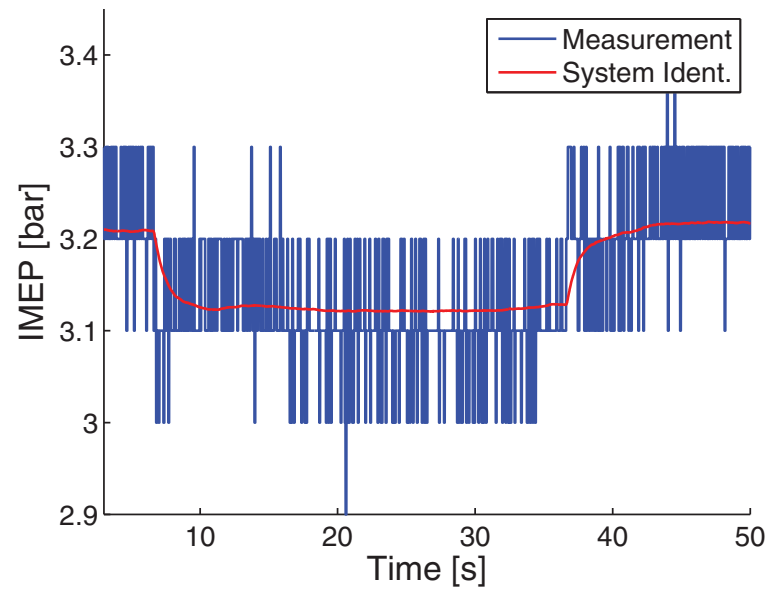

(a)

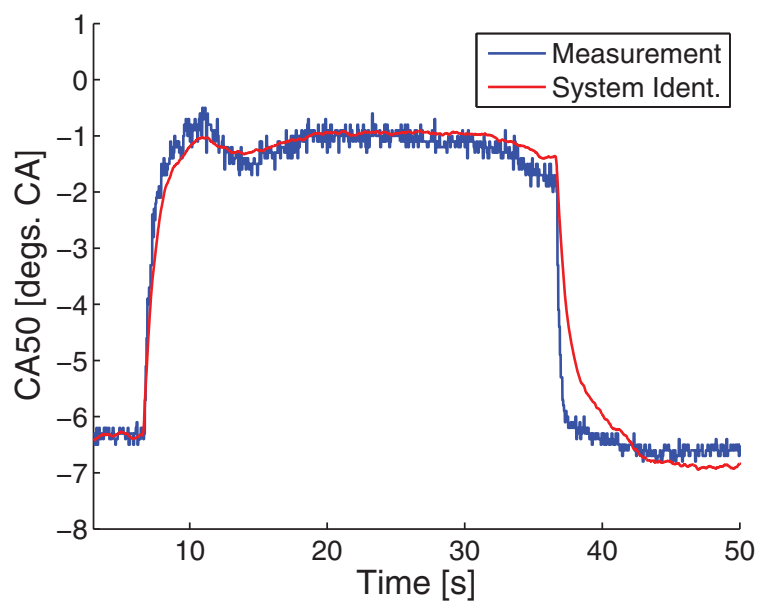

(b)

Fig. 11 Comparison between experiment and system identification with identified discrete transfer function $G(z)_{\mathrm{EGR},(0.01)}$. IMEP (left) and CA50 (right) for an EGR step from 30 to 45 per cent and back with an SOI of $-20.7 \mathrm{deg}$ CA aTDC and an injected fuel mass of $10.2 \mathrm{mg} /$ cycle

the stand-alone multi-zone model from within MATLAB $^{\circledR} /$ SIMULINK $^{\circledR}$. Moreover, the gas exchange model was also implemented into this s-function. The three identified dynamic transfer functions were added by means of time-discrete $P T_{1}$-dynamics within appropriate function blocks.

The simulation environment is realized such that the initial in-cylinder conditions reflect the engineout conditions of the prior cycle. This establishes the cycle-to-cycle connectivity. However, as the external EGR was cooled, the measurements did not show a strong dependency of the intake conditions on the engine-out conditions, except for the external
EGR composition when varying the total injected fuel mass. Figure 13 shows IMEP and CA50 obtained from the step response experiment, the system identification with the corresponding identified dis-

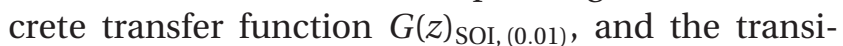
ent simulation with the integrated model using $G(z)_{\text {SOI, (0.06) }}$ for an SOI step from -20.7 to $-30.7 \mathrm{deg}$ CA aTDC and back with an external EGR rate of 30 percent and an injected fuel mass of $10.2 \mathrm{mg} /$ cycle. Figure 14 depicts the same except that the SOI step was applied from -40.7 to $-30.7 \mathrm{deg}$ CA aTDC. Finally, IMEP and CA50 for the step response experiment, for the system identification with the 


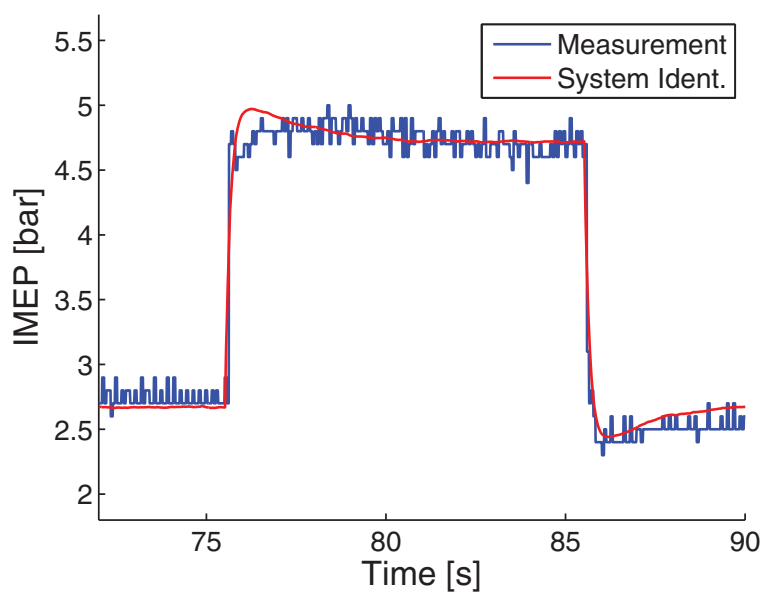

(a)

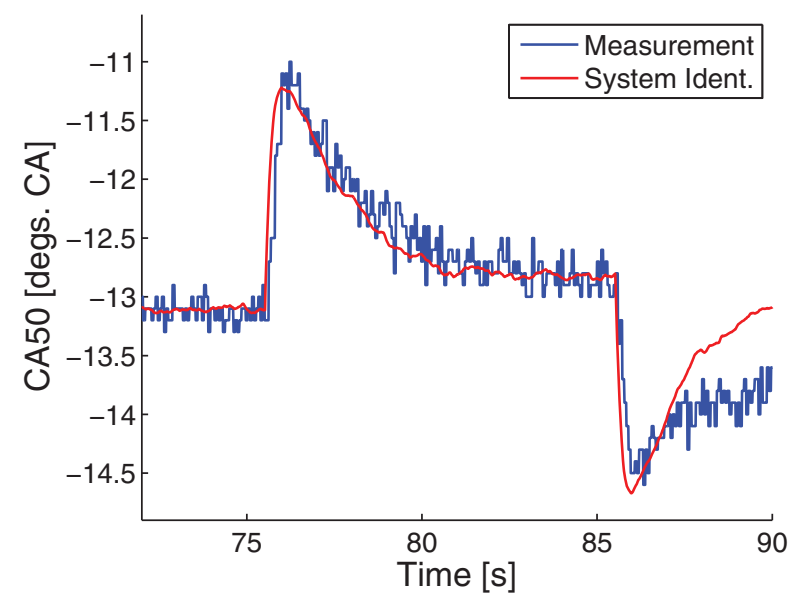

(b)

Fig. 12 Comparison between experiment and system identification with identified discrete transfer function $G(z)_{\mathrm{FMI},(0.01)}$. IMEP (left) and CA50 (right) for an injected fuel mass step from 10.2 to $17.0 \mathrm{mg} / \mathrm{cycle}$ and back with an SOI of $-35.7 \mathrm{deg}$ CA aTDC and an external EGR rate of 45 per cent

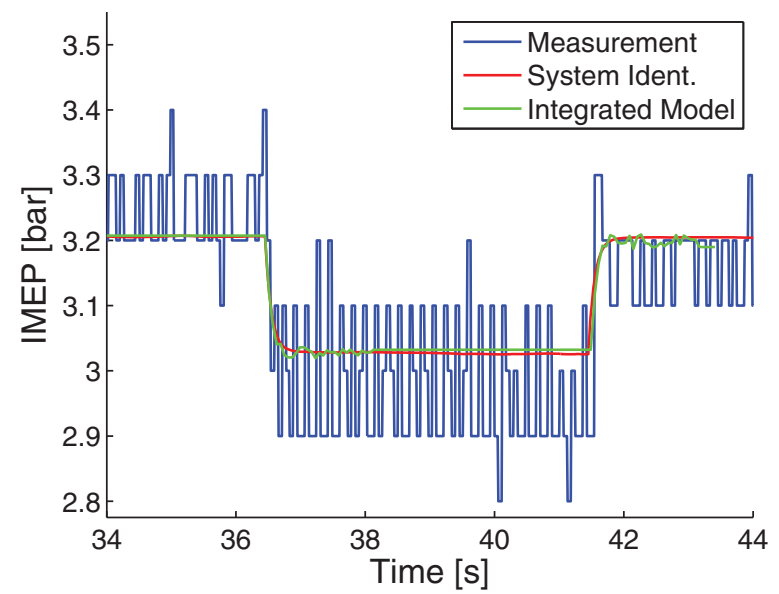

(a)

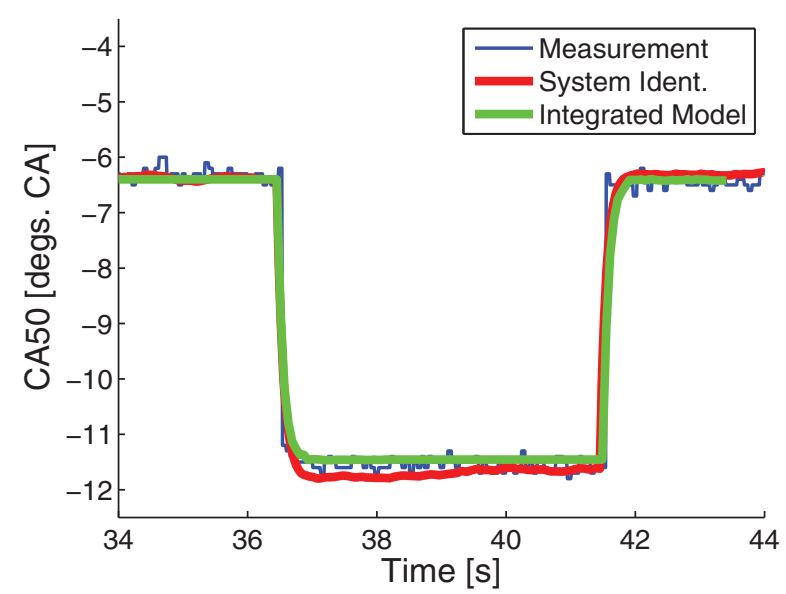

(b)

Fig. 13 IMEP (left) and CA50 (right) for an SOI step from -20.7 to -30.7 deg CA aTDC and back with an external EGR rate of 30 percent and an injected fuel mass of $10.2 \mathrm{mg} / \mathrm{cycle}$. Comparison between experiment, system identification, and integrated model

corresponding identified discrete transfer function

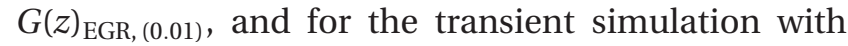
the integrated model using $G(z)_{\mathrm{EGR},(0.06)}$ are presented in Fig. 15 for an EGR step from 30 to 45 per cent and back with an SOI of -20.7 deg CA aTDC and an injected fuel mass of $10.2 \mathrm{mg} /$ cycle.

Fluctuations in the data from the integrated model that are most distinct for the IMEP of the simulated EGR step (see Fig. 15) are caused by the nonlinear behaviour of the multi-zone model. It reacts very sensitively to the input values, which are modified by the identified dynamic transfer functions. On the one hand, this emphasizes that the multi-zone model is an appropriate model since it even captures slight deviances in the input signals.
On the other hand, it is important that the multizone model does not overpredict effects of small disturbances. Obviously, this is not the case as shown in the presented figures.

The simulation results are in very good agreement with the measurements. In particular, the dynamic step responses are reproduced well. This validates the integrated model composed of the stand-alone multi-zone model, the gas exchange model, and the identified system dynamics.

The strict derivation of the stand-alone multizone model from a detailed three-dimensional CFD approach integrates the detailed knowledge from combustion simulation tools into closed-loop control. This novel procedure establishes a broad field 


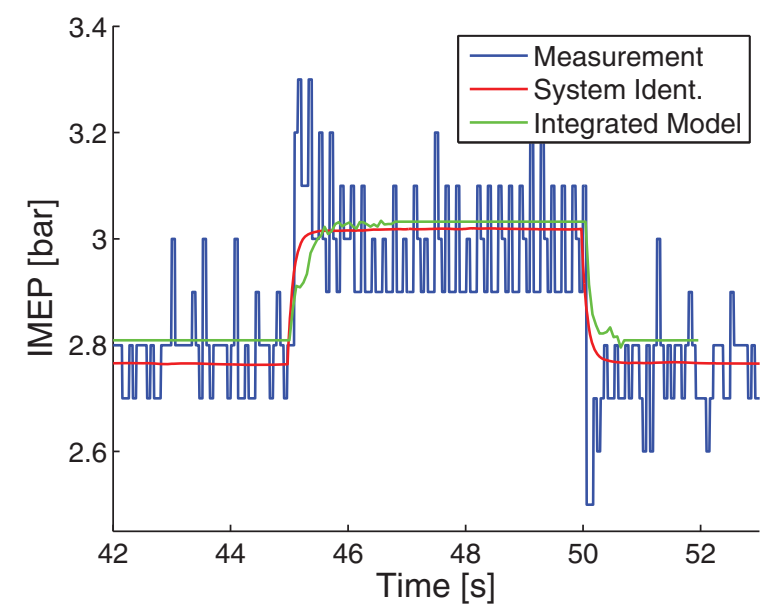

(a)

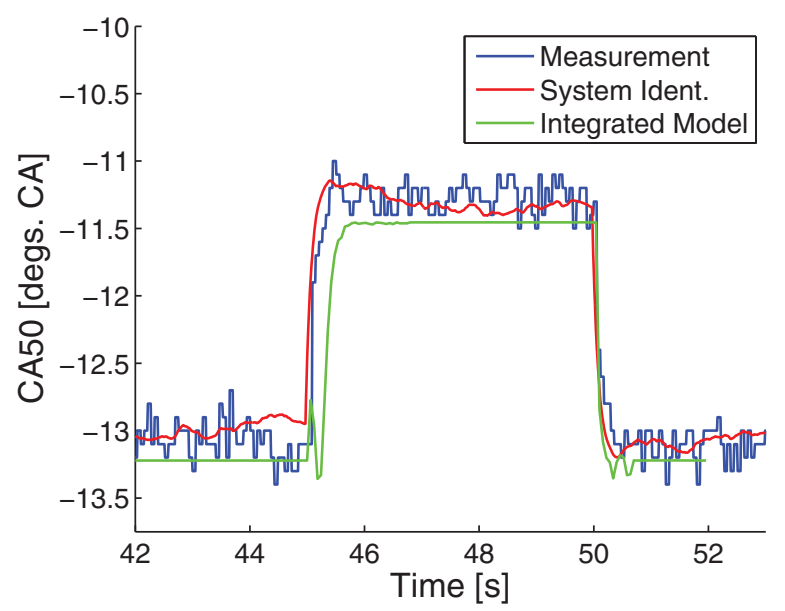

(b)

Fig. 14 IMEP (left) and CA50 (right) for an SOI step from -40.7 to -30.7 deg CA aTDC and back with an external EGR rate of 30 percent and an injected fuel mass of $10.2 \mathrm{mg} / \mathrm{cycle}$. Comparison between experiment, system identification, and integrated model

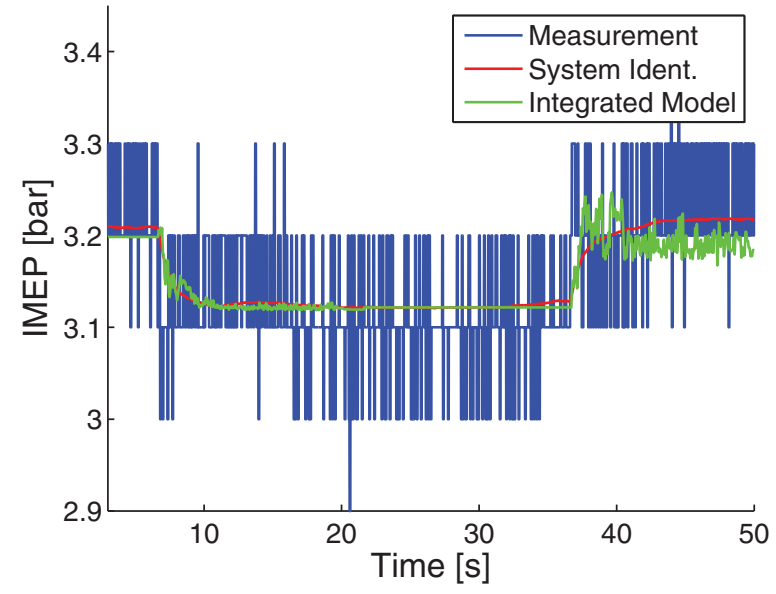

(a)

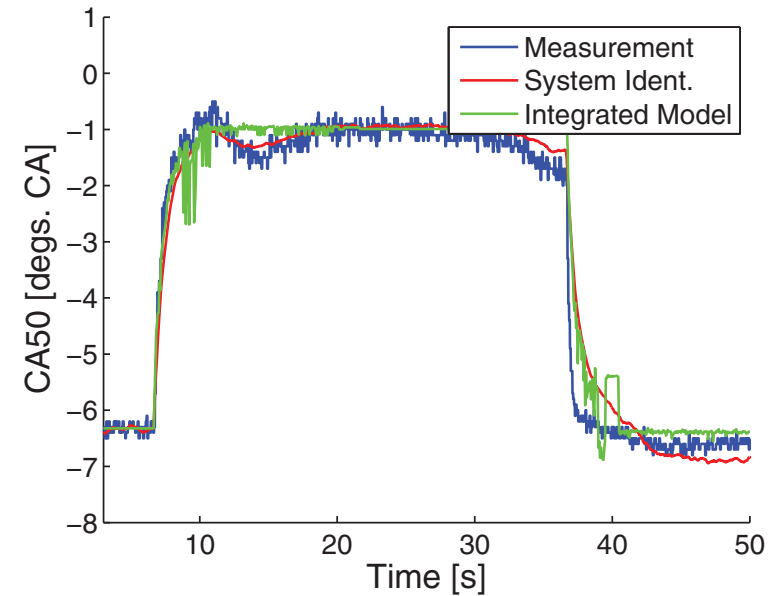

(b)

Fig. 15 IMEP (left) and CA50 (right) for an EGR step from 30 to 45 per cent and back with an SOI of $-20.7 \mathrm{deg}$ CA aTDC and an injected fuel mass of $10.2 \mathrm{mg} / \mathrm{cycle}$. Comparison between experiment, system identification, and integrated model

of possibilities for testing completely new controlled process variables. In this context, Fig. 16 displays further outcomes of the transient simulation for an SOI step from -20.7 to $-30.7 \mathrm{deg}$ CA aTDC and back with an external EGR rate of 30 per cent and an injected fuel mass of $10.2 \mathrm{mg} /$ cycle. Exemplary, the NO emissions, the maximum pressure, the burning time from CA10 to CA90, and the ringing intensity are shown.

The combustion noise level is quantified applying the ringing intensity correlation developed by Eng [44]. This correlation relates the ringing intensity to the maximum pressure rise rate, the maximum pressure, and the speed of sound. The ringing intensity is expressed as

$$
\text { RingingIntensity } \approx \frac{1}{2 \gamma} \frac{\left(\beta \frac{\mathrm{d} p}{\mathrm{~d} t} \max \right)^{2}}{p_{\max }} \sqrt{\gamma R T_{\max }}
$$

In equation (17), $\mathrm{d} p / \mathrm{d} t_{\max }$ denotes the maximum pressure rise rate, $p_{\max }$ the maximum pressure, and $T_{\max }$ the maximum temperature. $\beta$ is a scaling factor determined from the experimental data. In this work, it is set to $0.005 \mathrm{~ms}$. In [44], a value of $0.05 \mathrm{~ms}$ was applied.

Figure 16 reveals that the NO emissions increase with advanced SOI timings due to an increasing maximum pressure or maximum temperature, respectively. Advancing the SOI also increases the burning time. This reduces the pressure rise rate, leading to a 


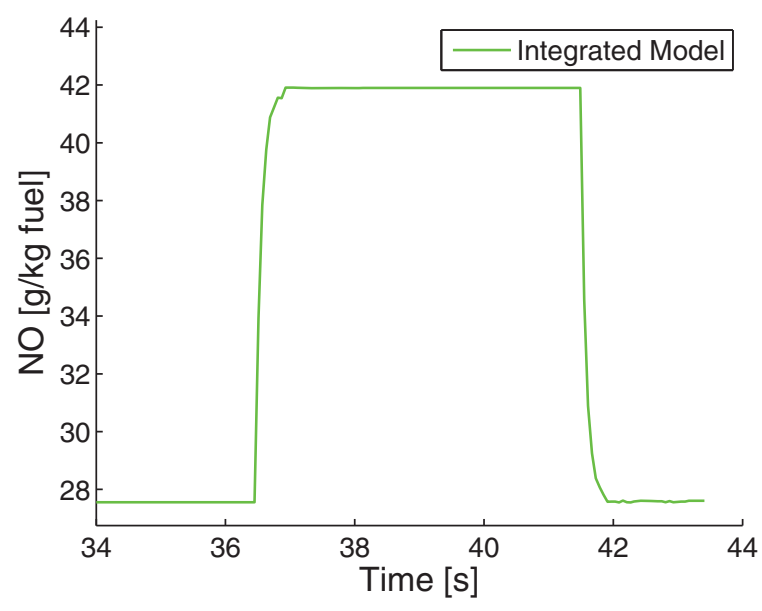

(a)

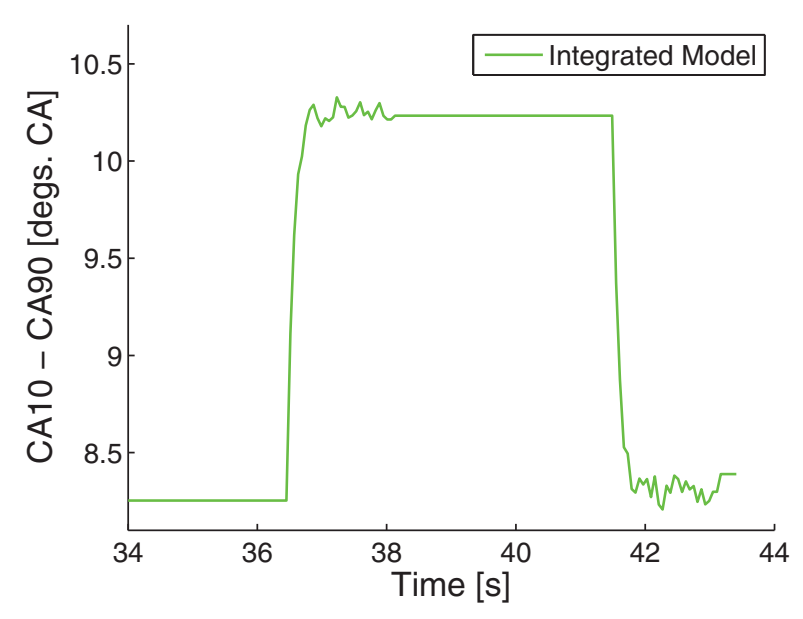

(c)

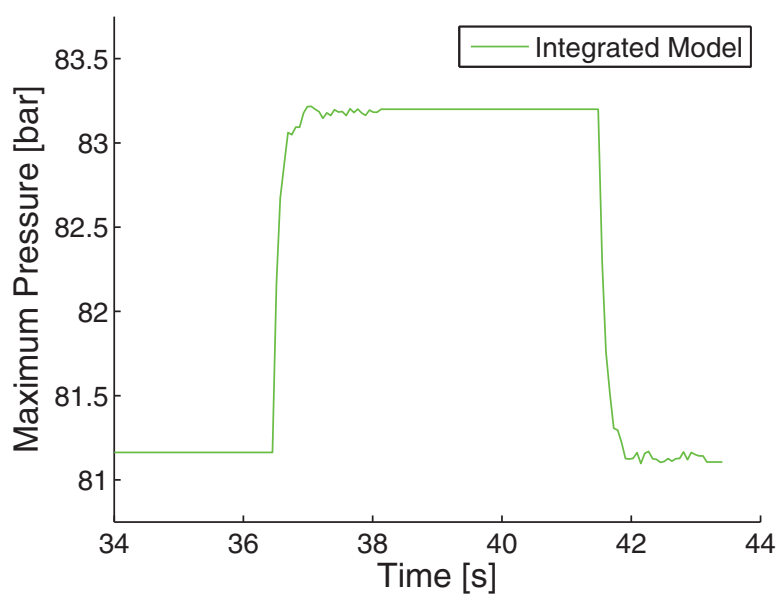

(b)

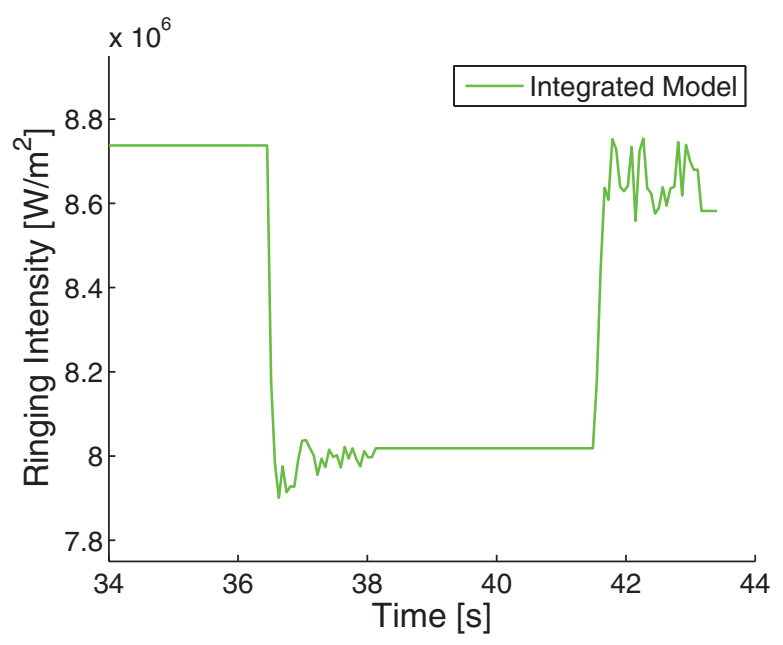

(d)

Fig. 16 Additional process variables obtained from a transient simulation with the integrated model. NO emissions, maximum pressure, burning time from CA10 to CA90, and ringing intensity (from top to bottom) for an SOI step from -20.7 to $-30.7 \mathrm{deg}$ CA aTDC and back with an external EGR rate of 30 per cent and an injected fuel mass of $10.2 \mathrm{mg} / \mathrm{cycle}$

decreasing ringing intensity. These results indicate the potential of the integrated model in the framework of closed-loop control development. Beyond the controlled variables IMEP and CA50, the integrated model is capable of predicting various additional process variables, with four selected ones being briefly discussed in this section. These additional process variables allow for defining further process constraints or may even replace the original controlled variables, depending on the specific control task.

\section{SUMMARY AND CONCLUSIONS}

Closed-loop simulations are a necessary and common tool in the development process of controllers. A computationally efficient stand-alone multi-zone model was employed that is capable of describing the combustion characteristics for the high-pressure part of the engine cycle. The controller to be developed shall actuate SOI, external EGR rate, and total fuel mass injected to control the IMEP of the whole engine cycle and the CA50. The IMEP ${ }_{\mathrm{HP}}$ of the highpressure engine cycle and the CA50 can be extracted from simulations with the stand-alone multi-zone model. The former was combined with a mean value model for the losses of the gas exchange to calculate the IMEP of the whole engine cycle. The combination of these models leads to an accurate static model, which was further extended to a Wiener model for capturing temporal cycle-to-cycle dependencies. For every input of the model, a transfer function was determined, forcing the whole model to follow the engine's dynamics. All model parts (stand-alone multi-zone model, mean value model for the gas 

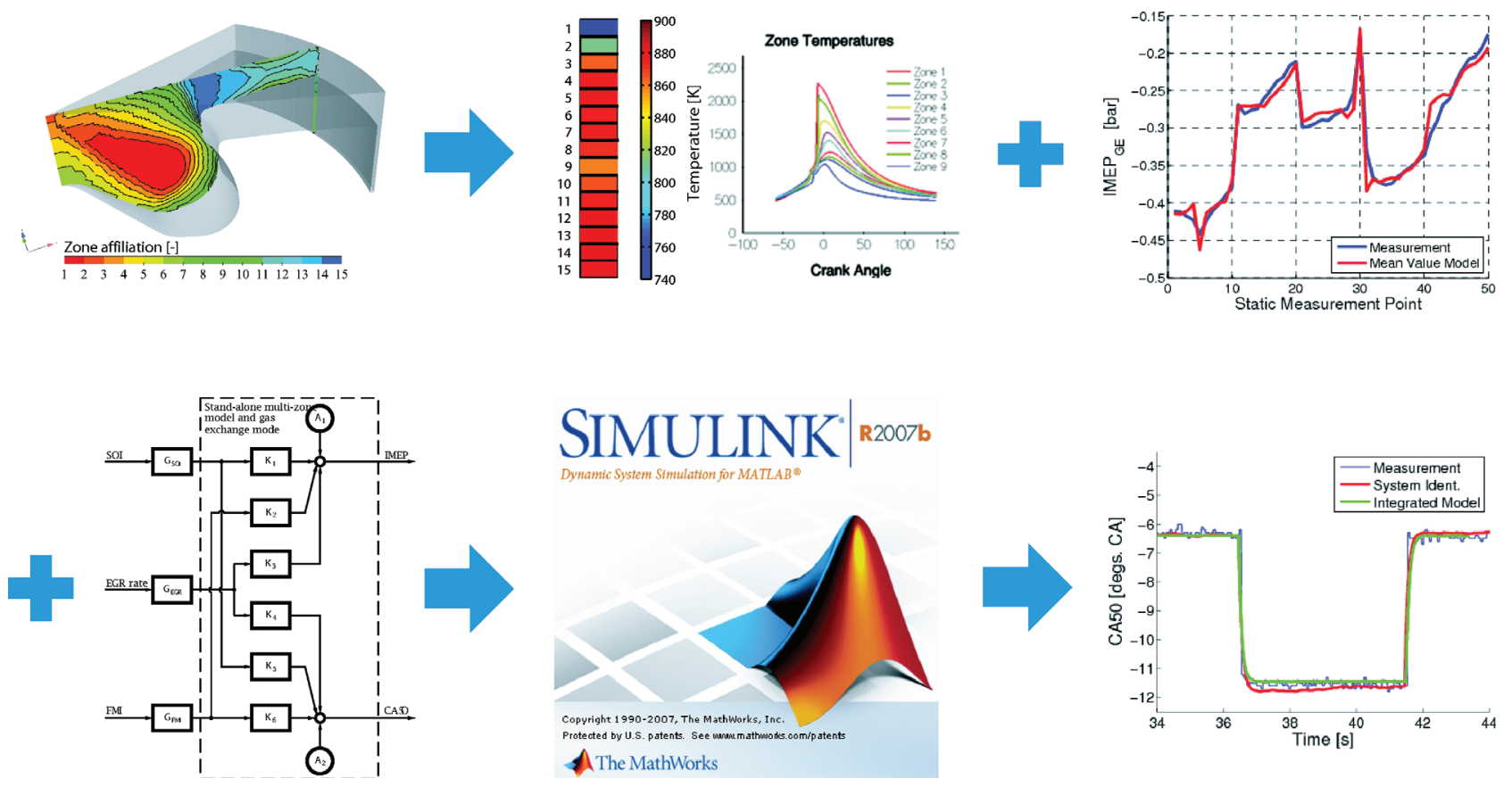

Fig. 17 Combustion modelling procedure for engine control applications

exchange, and dynamic time response) were each validated separately. Afterwards, the integrated model composed of all three model parts was validated against transient experimental data. The whole modelling procedure is illustrated in Fig. 17.

\section{FUTURE WORK}

Future experimental work will have to reveal additional transient experimental results (for example NO emissions, maximum pressure, burning time from CA10 to CA90, see Fig. 16) in order to further assess the performance of the integrated model.

The dynamic model will build the framework in which a controller for the PCCI combustion process will be developed. With the developed plant model, this controller will be laid out and tested.

The actuated variable external EGR rate is theoretical as long as there is no corresponding actor to it. Because of this, the overall goal of this research project (carried out within the Collaborative Research Centre SFB 686 - Modellbasierte Regelung der homogenisierten Niedertemperatur-Verbrennung at RWTH Aachen University, Germany, and Bielefeld University, Germany [45]) is to develop not only a controller for the PCCI combustion process, but also an additional controller enabling the fastest possible changes in external EGR rate by simultaneously adjusting EGR valve and VGT position. This controller, in combination with its actuated variables EGR valve and VGT position, will serve as the virtual actor for the external EGR rate. First corresponding results were already presented by Drews et al. [46, 47].

\section{ACKNOWLEDGEMENTS}

This work was funded by the German Research Foundation (DFG) within the Collaborative Research Centre SFB 686 - Model-Based Control of Homogenized Low-Temperature Combustion at RWTH Aachen University, Germany, and Bielefeld University, Germany [45].

(c) Authors 2011

\section{REFERENCES}

1 Davis, S. C., Diegel, S. W., and Boundy, R. G. Transportation energy data book, edition 28, Center for Transportation Analysis, Energy and Transportation Science Division, Oak Ridge National Laboratory, USA, 2009.

2 Harada, A., Shimazaki, N., Sasaki, S., Miyamoto, T., Akagawa, H., and Tsujimura, K. The effects of mixture formation on premixed lean diesel combustion. SAE paper 980533, 1998.

3 Iwabuchi, Y., Kawai, K., Shoji, T., and Takeda, Y. Trial of new concept diesel combustion system premixed compression ignited combustion. SAE paper 1999-01-0185, 1999. 
4 Takeda, Y. and Keiichi, N. Emission characteristics of premixed lean diesel combustion with extremely early staged fuel injection. SAE paper 961163, 1996.

5 Dec, J. E. Advanced compression-ignition engines - understanding the in-cylinder processes. Proc. Combust. Inst., 2009, 32, 2727-2742.

6 Bengtsson, J., Strandh, P., Johansson, R., Tunestål, P., and Johansson, B. Hybrid control of homogeneous charge compression ignition (HCCI) engine dynamics. Int. J. Control, 2006, 79, 422-448.

7 Hillion, M., Buhlbuck, H., Chauvin, J., and Petit, N. Combustion control of diesel engines using injection timing. SAE paper 2009-01-0367, 2009.

8 Hillion, M., Chauvin, J., Grondin, O., and Petit, N. Active combustion control of diesel HCCI engine: combustion timing. SAE paper 2008-01-0984, 2008.

9 Nakayama, S., Ibuki, T., Hosaki, H., and Tominaga, H. An application of a model based combustion control to transient cycle-by-cycle diesel combustion. SAE paper 2008-01-1311, 2008.

10 Narayanaswamy, K. and Rutland, C. J. A modeling investigation of combustion control variables during DI-diesel HCCI engine transients. SAE paper 2006-01-1084, 2006.

11 Shaver, G. M., Roelle, M. J., Caton, P. A., Kaahaaina, N. B., Ravi, N., Hathout, J.-P., Ahmed, J., Kojic, A., Park, S., Edwards, C. F., and Gerdes, J. C. A physics-based approach to the control of homogeneous charge compression ignition engines with variable valve actuation. Int. J. Engine Res., 2005, 6, 361-375.

12 Turin, R., Zhang, R., and Chang, M.-F. Systematic model-based engine control design. SAE paper 2008-01-0994, 2008.

13 Albrecht, A., Grondin, O., Le Berr, F., and Le Solliec, G. Towards a stronger simulation support for engine control design: a methodological point of view. Oil Gas Sci. Technol. - Rev. IFP, 2007, 62, 437-456.

14 Bengtsson, J., Strandh, P., Johansson, R., Tunestål, P., and Johansson, B. Hybrid modelling of homogeneous charge compression ignition (HCCI) engine dynamics - a survey. Int. J. Control, 2007, 80, 1814-1847.

15 Narayanaswamy, K., Hessel, R. P., and Rutland, C. J. A new approach to model DI-diesel HCCI combustion for use in cycle simulation studies. SAE paper 2005-01-3743, 2005.

16 Shaver, G. M., Gerdes, J. C., Roelle, M. J., Caton, P. A., and Edwards, C. F. Dynamic modeling of residual-affected homogeneous charge compression ignition engines with variable valve actuation. J. Dynam. Syst., Meas., Control, 2005, 127, 374-381.

17 Shaver, G. M., Roelle, M. J., and Gerdes, J. C. Modeling cycle-to-cycle dynamics and mode transition in HCCI engines with variable valve actuation. Control Engng Pract., 2006, 14, 213-222.

18 Barths, H., Hasse, C., and Peters, N. Computational fluid dynamics modelling of non-premixed combustion in direct injection diesel engines. Int. J. Engine Res., 2000, 1, 249-267.

19 Colin, O. and Benkenida, A. The 3-zones extended coherent flame model (ECFM3Z) for computing premixed/diffusion combustion. Oil Gas Sci. Technol. - Rev. IFP, 2004, 59, 593-609.

20 Pope, S. B. PDF methods for turbulent reactive flows. Prog. Energy Combust. Sci., 1985, 11, 119-192.

21 Reitz, R. and Rutland, C. J. Development and testing of diesel engine CFD models. Prog. Energy Combust. Sci., 1995, 21, 173-196.

22 Barths, H., Felsch, C., and Peters, N. Mixing models for the two-way-coupling of CFD codes and zero-dimensional multi-zone codes to model HCCI combustion. Combust. Flame, 2009, 156, 130-139.

23 Felsch, C., Dahms, R., Glodde, B., Vogel, S., Jerzembeck, S., Peters, N., Barths, H., Sloane, T., Wermuth, N., and Lippert, A. M. An interactively coupled CFD-multi-zone approach to model HCCI combustion. Flow, Turbul. Combust., 2009, 82, 621-641.

24 Felsch, C., Hoffmann, K., Vanegas, A., Drews, P., Barths, H., Abel, D., and Peters, N. Combustion model reduction for diesel engine control design. Int. J. Engine Res., 2009, 10, 359-387.

25 Hergart, C.-A., Barths, H., and Siewert, R. M. Modeling approaches for partially premixed compression ignition combustion. SAE paper 2005-010218, 2005

26 Felsch, C., Sloane, T., Han, J., Barths, H., and Lippert, A. M. Numerical investigation of recompression and fuel reforming in a SIDI-HCCI engine. SAE paper 2007-01-1878, 2007.

27 Woschni, G. A universally applicable equation for instantaneous heat transfer coefficients in the internal combustion engine. SAE paper 670931, 1967.

28 Baehr, H. D. and Stephan, K. Wärme- und Stoffübertragung, 2006 (Springer, Berlin).

29 Felsch, C., Vanegas, A., Kerschgens, B., Peters, N., Hoffmann, K., Drews, P., Abel, D., and Barths, H. Systematic reduction of an interactively coupled CFD-multi-zone approach towards a stand-alone multi-zone model for PCCI combustion. In Proceedings of the Conference on Thermo-and fluid dynamic processes in diesel engines, Universidad Politécnica de Valencia, Valencia, Spain, 2008.

30 Peters, N., Paczko, G., Seiser, R., and Seshadri, K. Temperature cross-over and non-thermal runaway at two-stage ignition of n-heptane. Combust. Flame, 2002, 28, 38-59.

31 Heywood, J. B. Internal engine combustion fundamentals, 1988 (McGraw-Hill, New York).

32 Vanegas, A., Won, H., Felsch, C., Gauding, M., and Peters, N. Experimental investigation of the effect of multiple injections on pollutant formation in a common-rail DI diesel engine. SAE paper 2008-011191, 2008.

33 Ricardo Software. WAVE Basic Manual, Documentation/User's Manual, Version 5.0. Technical report, Ricardo Software, 2003. 
34 Gamma Technologies. GT-POWER User's Manual and Tutorial, GT-SUITE Version 7.0. Technical report, Gamma Technologies, 2008.

35 Hoffmann, K., Drews, P., Abel, D., Felsch, C., Vanegas, A., and Peters, N. A cycle-based multizone simulation approach including cycle-to-cycle dynamics for the development of a controller for PCCI combustion. SAE paper 2009-01-0671, 2009.

36 Richert, F. Objektorientierte Modellbildung und Nichtlineare Prädiktive Regelung von Dieselmotoren. PhD thesis, RWTH Aachen University, Germany, 2005.

37 Nelles, 0. Nonlinear system identification: from classical approaches to neural networks and fuzzy models, 2000 (Springer, Berlin).

38 Peréz, E., Blasco, X., García-Nieto, S., and Sanchis, J. Diesel engine identification and predictive control using Wiener and Hammerstein models. In Proceedings of the 2006 IEEE International Conference on Control applications, Munich, Germany, 2006.

39 Schulze, T., Wiedemeier, M., and Schuette, $\mathbf{H}$. Crank angle-based diesel engine modeling for hardware-in-the-loop applications with in-cylinder pressure sensors. SAE paper 2007-01-1303, 2007.

40 ETAS GmbH. ES 1000.3 Benutzerhandbuch. Technical report, ETAS GmbH, 2008.

41 Guzzella, L. and Onder, C. H. Introduction to modeling and control of internal combustion engine systems, 2004 (Springer, Berlin).

42 IAV GmbH Ingenieursgesellschaft Auto und Verkehr. FI2RE - Flexible Injection and Ignition for Rapid Engineering. Available from http://www. iav.com/de/1_engineering/powertrainmechatronik/ messtechnik/fi2re.php, 2008.

43 Lunze, J. Regelungstechnik 2: Mehrgrößensysteme, Digitale Regelung, 2008 (Springer, Berlin).

44 Eng, J. A. Characterization of pressure waves in HCCI combustion. SAE paper 2002-01-2859, 2002.

45 RWTH Aachen University and Bielefeld University. SFB 686 - Modellbasierte Regelung der homogenisierten Niedertemperatur-Verbrennung, since 2006. Available from http://www.sfb686.rwth-aachen.de.

46 Drews, P., Albin, T., Hoffmann, K., Vanegas, A., Felsch, C., Peters, N., and Abel, D. Model-based optimal control for PCCI combustion engines. In Proceedings of the IFAC Symposium on Advances in automotive control, Munich, Germany, 2010.

47 Drews, P., Hoffmann, K., Beck, R., Gasper, R., Vanegas, A., Felsch, C., Peters, N., and Abel, D. Fast model predictive control for the air path of a turbocharged diesel engine. In Proceedings of the European Control Conference, 2009, Budapest, Hungary.

\section{APPENDIX}

\section{Notation}

aTDC

CA

CA10

CA50

CFD

$\mathrm{CO}$

ECU

EGR

EOI

EVO

FMI

HCCI

IMEP

IMEP $_{\mathrm{GE}}$

$\mathrm{IMEP}_{\mathrm{HP}}$

IVC

LTC

$\mathrm{NO}_{x}$

$p_{\mathrm{ae}}$

$p_{\text {be }}$

PCCI

PCI

$P T_{1}$-element

$\mathrm{r} / \mathrm{min}$

RWTH

SOI

$T_{\mathrm{ae}}$

$T_{\text {be }}$

TDC

TS

VGT

XOD after top dead centre

crank angle

crank angle of 10 per cent burnt mass

crank angle of 50 per cent burnt mass

computational fluid dynamics

carbon monoxide

electronic control unit

exhaust gas recirculated

end of injection

exhaust valve opening

total fuel mass injected

homogeneous charge compression

ignition

indicated mean effective pressure

indicated mean effective pressure of

the gas exchange

indicated mean effective pressure of the high-pressure cycle

intake valve closure

low-temperature combustion

nitrogen oxides

pressure in the exhaust manifold

(after engine)

pressure in the intake manifold

(before engine)

premixed charge compression

ignition

premixed charge ignition

first-order lag element

revolutions per minute

Rheinisch Westfälische Technische

Hochschule Aachen

start of injection

temperature in the exhaust manifold

temperature in the intake manifold

top dead centre

timing sweep

variable geometry turbine

multi-zone chemistry model 